Elsevier required licence: (C2016. This manuscript version is made available under the CC-BY-NC-ND 4.0 license http://creativecommons.org/licenses/bync-nd/4.0/ 


\section{Management control effectiveness and strategy: An empirical analysis of packages and systems}

\section{Introduction}

The interface between management control (MC) and strategy is one of the most enduring concerns in management accounting literature. Much of the research in this space follows a contingency approach to establish systematic associations between strategy and particular MC practices. However, while the literature has been relatively successful in identifying associations between strategy and individual MC practices, little progress has been made towards understanding the choice and consequences of combinations of MC practices in different strategic contexts (Langfield-Smith, 2008). This study seeks to add to the limited body of knowledge in this area by addressing two related questions.

The first research question this study explores is how a set of $M C$ practices combine as a package to achieve effective control outcomes in different strategic contexts. ${ }^{1}$ Prior MC-strategy research predominately examines $M C$ practices in isolation. The implicit assumption is that an understanding of effective MC packages can be gained by aggregating the results of independent analyses of MC practices (Donaldson, 2001). Yet without empirical evidence it remains less than clear whether all MC practices found to be relevant separately are in fact relevant when examined simultaneously as a package. MC practices observed to have incremental benefits in isolation may not necessarily be relevant for achieving effective control outcomes when analysed as part of the wider set of MC practices that a firm has in place.

Observing a coexisting set of MC practices does not, however, imply interdependence between MC practices (Grabner \& Moers, 2013). The second question of this study is therefore which, if any, MC practices within a package form interdependent systems and how these vary across different strategic contexts. While it is generally assumed that accounting and other $\mathrm{MC}$ practices are interdependent (Chenhall \& Moers, 2015; Milgrom \& Roberts, 1995; Otley, 1980), most MC-strategy literature relies on conventional contingency approaches which maintain that the effectiveness of any one MC practice is determined by contextual factors (Donaldson, 2001). This approach ignores the possibility that the benefits of using $M C$ practices may depend not only on the fit with strategy but also upon how MC practices fit with each other. Furthermore, as strategy influences the effectiveness of individual MC practices it is plausible that the strategic context of a firm will also affect the degree of interdependence between MC practices (Grabner, 2014; Grabner \& Moers, 2013). For instance, MC practices observed to act as complements in one strategic context may be unrelated or act as substitutes in another.

There are two empirical approaches for addressing these questions. One approach, implicit in the discussion of Grabner and Moers (2013), is to examine specific MC practices (i.e. as a system) to develop an understanding of which $\mathrm{MC}$ practices are interdependent and which are independent within a package. The second approach is to start with an aggregate investigation of MC practices (i.e. as a package) to identify which MC practices are likely to act as complements or substitutes and then subject these to more specific analyses. ${ }^{2}$ This study adopts the latter approach. This more exploratory approach is appropriate given that there is little empirical or theoretical knowledge to indicate how the numerous MC practices examined in MC-strategy literature may or may not be related.

To address the first research question this study applies fuzzy set qualitative comparative analysis (fsQCA). Unlike techniques previously used to investigate $M C$ packages, such as cluster

\footnotetext{
${ }^{1}$ In this study a MC package refers to the set of MC practices top managers use to meet the control requirements of a particular strategy, whereas a MC system refers to MC practices that are interdependent, that is, where the benefit of one MC practice depends on the value of another (Grabner \& Moers, 2013). ${ }^{2}$ The analysis of MC as a package is consistent with configuration theory (Fiss, 2011; Gerdin \& Greve, 2004), while the analysis of MC as a system is consistent with complementarity theory (Grabner \& Moers, 2013; Milgrom \& Roberts, 1995).
} 
analysis, this approach reveals which MC practices are relevant, and which are redundant, for achieving effective control in a particular strategic context (Ragin, 2008). Using data from 400 responses by top managers to a cross-sectional survey, and drawing on the framework of Miles and Snow (1978), this study reveals that firms in defender and prospector strategic contexts can combine $M C$ practices in multiple and equally effective ways. Furthermore, it is found that not all MC practices within a package are relevant for achieving effective control outcomes.

The analysis of MC packages provides the basis for examining the second research question. Although interdependence cannot be established directly from the first analysis, comparison of the similarities and differences in the relevance of $M C$ practices between effective $M C$ packages provides information about which practices are likely to act as complements or substitutes. Based on this comparison theory is developed to explain how and why certain MC practices within the observed packages operate interdependently. Predicted interdependencies are then examined through the production function approach to complementarity outlined by Grabner and Moers (2013). It is shown that for firms prioritizing efficiency and conformance (i.e. defenders) a diagnostic control use of accounting and mechanistic structural controls act as complements, while mechanistic structural controls and measure diversity act as substitutes. For firms emphasizing innovation and flexibility (i.e. prospectors) there is a complementary effect between an interactive control use of accounting and organic structural controls.

This study contributes to the literature in the following ways. First, the study extends the MC-strategy literature by demonstrating that not all MC practices observed to be beneficial in isolation need to be simultaneously present in a package to achieve effective control outcomes. This suggests that relying on the results of independent analyses of $\mathrm{MC}$ practices alone is insufficient for understanding the constitution of effective MC packages (Grabner \& Moers, 2013; Malmi \& Brown, 2008). Second, in showing that there are multiple and equally effective ways to combine $M C$ practices in the same strategic context this study provides empirical evidence of equifinality (Gerdin, 2005; Sandelin, 2008). This finding implies that conventional contingency approaches are unlikely to provide a complete understanding of the range of viable $\mathrm{MC}$ alternatives available to firms in a given context (Dent, 1990).

Third, this study adds to the emerging body of research investigating systematic interdependencies between MC practices (Abernethy et al., 2015; Campbell, 2012; Grabner, 2014; Indjejikian \& Matějka, 2012; Moers, 2006). This study shows that not only are accounting control and structural control choices interdependent, but that these interdependencies differ depending on the strategic context of the firm. However, the results also suggest that most of the MC practices examined are not interdependent; instead they appear to vary independently with the strategic context of the firm. This supports the claim of Indjejikian and Matějka (2012) that the assumed prevalence of complementarity between MC practices within a package is likely overstated. Finally, this study demonstrates how the analysis of MC packages, through the application of fsQCA, can be used to inform theory development and empirical analysis of MC systems. This provides an alternative approach for extending our understanding of how $M C$ practices are related to each other, and the conditions in which these interdependencies hold, than currently advocated in the literature (cf. Grabner \& Moers, 2013).

The remainder of this study is structured in two main parts. The first part (Section 2) details the exploratory analysis of $\mathrm{MC}$ packages. This section starts with an outline of the relevant literature and the research framework, followed by a description of the research method. The results of the MC package analysis are then presented. The second part (Section 3) outlines the analysis of MC systems. This section begins by describing how the analysis of $\mathrm{MC}$ packages will inform the analysis of $\mathrm{MC}$ systems. Predictions about MC practice interdependencies are then developed, followed by the research method and results. Section 4 provides a discussion and conclusion.

\section{Analysis of MC packages}


The first research question of this study examines how a set of MC practices combine as a package to achieve effective control outcomes in different strategic contexts. To explore this question a research framework is first outlined that details the choice of strategic typology, the selection of MC practices, and how the effectiveness of MC packages is conceptualised. The research method and results of the MC package analyses follow.

\subsection{Research framework}

\subsubsection{Strategic context}

To examine associations between MC and strategy much of the literature builds upon strategic typologies. These allow researchers to empirically capture the complex patterns of action and distinctive competencies that constitute the strategy of a firm (Chapman, 1997; Dent, 1990). This study uses the Miles and Snow (1978) typology, which is appropriate for a number of reasons. First, it describes the most prominent strategic postures adopted by firms in relation to their task environments and is closely associated with many of the contingent conditions that influence $\mathrm{MC}$ practice choices (Chenhall, 2003; Dent, 1990). Second, it is the most widely applied strategic typology (Hambrick, 2003), with a fairly extensive body of literature investigating the MC practices used by firms pursuing different product-market orientations (Langfield-Smith, 2008). Third, the typology is comparable to other strategic frameworks applied in MC-strategy literature (LangfieldSmith, 2008). Finally, it retains robust empirical correspondence (Desarbo et al., 2005; Kabanoff \& Brown, 2008) and is applicable to a wide range of industries (Hambrick, 2003; Simons, 1987).

\subsubsection{MC practices}

Prior MC-strategy research identifies systematic associations between strategy and a range of $\mathrm{MC}$ practices, with most of these analyses examining $M C$ practices in isolation. This study examines whether those $\mathrm{MC}$ practices found to be relevant independently are in fact relevant when analysed simultaneously as a package. The selection of $\mathrm{MC}$ practices is therefore based on empirical evidence in the literature. Specifically, MC practices are included in the analysis if there are at least two empirical studies reporting systematic associations with strategy. There are two qualifications to this. First, some MC practices examined in early MC-strategy research are excluded because they have significant overlap with more contemporary concerns. For instance, early research examines the use of cost information whereas more recent investigations are concerned with measure diversity (Langfield-Smith, 2008).

Second, the MC-strategy literature is mainly focused on the analysis of $M C$ practices in mutually exclusive strategic settings (i.e. defenders and prospectors) with little empirical analysis of joint or hybrid strategies where firms pursue multiple strategic objectives (i.e. analyzers). Research examining analyzer-type strategies is limited to the choice and use of performance measures and use of performance-based incentives (Bedford, 2015; Dekker et al., 2013; Lillis \& van Veen-Dirks, 2008). Given that it is generally unclear from prior research as to what other MC practices are expected to have benefits for analyzer firms, this study limits the analysis to defender and prospector strategic contexts. ${ }^{3}$ The MC practices selected for analysis and their supported associations are detailed in Table $1 .^{4}$

\section{<Insert Table 1 about here>}

A review of Table 1 suggests that the MC-strategy literature exhibits a reasonably consistent body of findings (Chenhall, 2003; Langfield-Smith, 2008). Firms following strategies characterized by

\footnotetext{
${ }^{3}$ Reactors are also excluded as this is a residual category for firms that do not have a consistent strategic pattern (Miles \& Snow, 1978).

${ }^{4} \mathrm{MC}$ practices are classified as accounting, compensation, administrative, or cultural, which cover the main categories of MC (Fisher, 1995; Flamholtz, 1983; Malmi \& Brown, 2008; Merchant \& Van der Stede, 2012).
} 
conservatism, cost leadership and efficiency are generally associated with mechanistic structural controls, a diagnostic control use of accounting information that focuses on financial and cost metrics, and the use of objectively determined performance-based pay. Firms that pursue strategies emphasizing product differentiation, innovation and entrepreneurship are associated with organic structural controls, an interactive control use of accounting information that incorporates broad scope measures, higher levels of performance-based pay that is more subjectively determined, and a greater emphasis on informal and cultural controls. The main exception concerns the association between tight accounting controls and prospector-type strategies. Some studies support initial theoretical predictions that prospectors use loose accounting controls (Auzair \& Langfield-Smith, 2005; Van der Stede, 2000), while others find that prospectors are most effective with the use of tight accounting controls (Chenhall \& Morris, 1995; Simons, 1987).

\subsubsection{MC effectiveness}

In MC-strategy research the implications of MC practices are typically evaluated through some measure of firm performance such as financial returns (Langfield-Smith, 2008). While financial performance is an obvious concern for most firms, to assess interdependence the measure of performance should relate directly to the benefits derived from the choice of MC practices. As such aggregate measures of firm performance are ill-suited for this purpose (Grabner and Moers, 2013). ${ }^{5}$ Instead this study examines the outcomes of MC practices in terms of their effectiveness in resolving the control problems associated with a given strategic context.

The primary function of $\mathrm{MC}$ is the alignment of individual and group behaviours towards intended objectives (Speklé, 2001). Flamholtz $(1983$, p. 157) has alluded to the operationalization of this function, commenting that it may be "useful to conceive of 'control' as a variable, where the amount of control is a function of the configuration of control system elements". However, the literature recognizes that control problems vary between firms. At a top management level, these control problems are neatly summarized by Otley and Berry (1980, p. 232), who define MC as:

[T]hose procedures which act to maintain viability through goal achievement, those concerned with the coordination and integration of differentiated parts, and those which promote adaptation to both internal and external change.

This definition indicates that $\mathrm{MC}$ is concerned with resolving three main problems: goal alignment, adaptability, and integration. ${ }^{6}$ The outcome variable in this study assesses the effectiveness of a combination of MC practices in resolving these control problems. Variable measurement is discussed further in the following section.

\subsection{Research method}

\subsubsection{Data collection}

Data for the empirical analysis were collected through a cross-sectional survey. The initial sample is the member database of the Certified Practicing Accountants of Australia (CPAA). A

\footnotetext{
${ }^{5}$ Firm performance captures not only the benefits of MC practices but also their adoption costs as well as factors unrelated to MC practice choices (Grabner \& Moers, 2013). Firm performance is thus a noisy measure, at best, for assessing interdependence, and at worst may contain systematic bias.

${ }^{6}$ These control problems relate closely to prior conceptualizations of MC (Ahrens \& Chapman, 2004; Emmanuel et al., 1990; Galbraith, 1973; Kloot, 1997; Simons, 1995). Goal alignment refers to the desire for predictable and efficient achievement of firm objectives (Duncan, 1973; Simons, 1995). Adaptability relates to the capacity of the firm to respond to variations in the external environmental and to flexibly adjust to novel and innovative behaviours (Hrebiniak \& Joyce, 1985; Simons, 1995). Integration refers to coordination among different parts of the firm to accomplish collective tasks (Barki \& Pinsonneault, 2005; Lawrence \& Lorsch, 1967; Van de Ven et al., 1976).
} 
random selection of 1500 individual firms and respondents meeting the following four criteria were identified from the database. First, as the focus of this study is on business-level strategy, firms are independent organizations or strategic business units (SBU). ${ }^{7}$ Organizational forms such as holding companies or multi-divisional corporations are excluded as these are not comparable in relation to either strategy or MC requirements. Second, firms have a minimum of 100 employees and revenues of at least $\$ 20$ million to ensure that formal accounting and other MC practices are in place. Third, firms are for-profit. The framing of a number of questions, notably strategy, are less applicable to non-profit firms that pursue fundamentally different objectives. Fourth, respondents are members of the top management team as they are likely to have the most comprehensive understanding of $\mathrm{MC}$ and strategy. ${ }^{8}$ Additional cross-checks of these criteria against Dun and Bradstreet and Hoovers databases resulted in the removal of 107 firms, leaving a sampling frame of 1393.

Respondents were contacted by telephone with surveys mailed to the 911 managers that agreed to participate. In total 421 surveys (46.2 percent) were returned. ${ }^{9}$ Some responses are removed if they fail to meet the criteria of this study or contain significant missing data (e.g. a page or more). Surveys with one or more values that appear to have been missed inadvertently are retained, with values imputed using the expectation-maximization process (Hair et al., 2006). The final sample contains 400 responses. Demographic information is provided in Table 2.

$<$ Insert Table 2 about here $>$

Two checks for non-response bias are conducted. First, the construct means between the first and last 20 percent of surveys received are compared with no meaningful differences found. Second, the size and industry of respondent firms are compared to the sample population. No significant differences are identified. A number of steps were taken to address common-rater bias (Podsakoff et al., 2003). ${ }^{10}$ First, the survey instrument was extensively pilot tested to assess consistency in interpretation and to remove ambiguity in item wording. Second, different scale endpoints and formats are used. Third, Harman's one-factor test shows that the first factor in an unrotated factor solution explains considerably less than half of the overall variance, suggesting that single-source bias is not a significant concern.

\subsubsection{Construct measurement}

Existing instruments are drawn upon where possible. Refinements or development of new constructs are made with reference to the measurement guidelines of Rossiter (2002) and Jarvis et al. (2003). The survey instrument was subject to pre-testing with 10 senior managers and 9 academics to evaluate face and content validity. The validity of reflective constructs is further assessed through (1) factor analysis, (2) correlation analysis, and (3) Cronbach's Alpha. Factor analysis using maximum-likelihood extraction and oblique rotation supports unidimensionality for each construct. The correlation matrix, shown in Table 3, presents plausible associations between

\footnotetext{
${ }^{7}$ This definition of a firm is consistent with prior MC-strategy research (e.g. Chenhall, 2005; Chenhall \& Langfield-Smith, 1998; Henri, 2006a).

${ }^{8}$ Consistent with prior literature top management team is defined as the top two tiers of a firm's management structure (e.g. CEO, GM, COO, CFO, and the next highest level of management) (Henri, 2006a). Given the use of the CPAA database most respondents in the second tier of management assume senior accounting or finance positions.

${ }^{9}$ Survey design and implementation followed the approach of Dillman (2000). Respondents were initially contacted by telephone to ensure that the firm characteristics and respondent position and knowledge are suitable for this study. A mail-out package containing a cover letter, the questionnaire and a prepaid return envelope were sent out within a week of contact to those that agreed to participate. All respondents were sent a reminder postcard one and a half weeks after initial mailing, while a second follow-up phone call was made to those who had yet to reply.

${ }^{10}$ When examining interaction terms (e.g. to test for MC practice interdependence) common methods bias is less of a concern because it contributes to deflating, not inflating, statistical significance (Siemsen et al., 2009).
} 
constructs. Only one correlation, between interactive and diagnostic control uses of accounting, is above 0.6. This correlation is consistent with those reported in prior literature (cf. Henri, 2006a; Widener, 2007). Cronbach Alpha's are between 0.78 and 0.89 supporting construct reliability. The validity of formative constructs is assessed through (1) principal component analysis (PCA) weightings, and (2) variance inflation factors (VIFs) (Petter et al., 2007). PCA reveals all formative construct items are positive and have weights above the recommended minimum of 0.30 (Hair et al., 2006). The maximum VIF of 2.32 is well below the general threshold of 10 (Hair et al., 2006). Survey items are reported in Appendix $A$.

$<$ Insert Table 3 about here>

Diagnostic control and interactive control uses of accounting information are assessed through top management use of budgets and performance measurement systems (PMS). The focus on budgets and PMS is appropriate as they are the most common sources of accounting information at the top management level and are empirically associated with strategy (Abernethy \& Brownell, 1999; Bisbe \& Otley, 2004; Henri, 2006a; Widener, 2007). ${ }^{11}$ Items for diagnostic control and interactive control uses were responded to separately for budgets and PMS, with the average score taken if the firm uses both systems. Diagnostic control use is assessed through a reflective measurement model containing five items adapted from Henri (2006a) and Widener (2007). Factor analysis reveals loadings $>0.75$ of all items on a single factor (Var. 69.6\%, $\alpha=0.89$ ). Interactive control use is based on the formative measurement model outlined by Bisbe et al. (2007) who identify five constitutive dimensions. Each dimension is captured by using single items adapted from prior literature (Abernethy \& Brownell, 1999; Bisbe \& Otley, 2004; Henri, 2006a; Widener, 2007).

Tightness of accounting controls is based on Merchant's (1985) conception of tight versus loose control. Merchant outlines four defining attributes of tightness. A single indicator is used to capture each dimension, relating to target flexibility, communication of targets, monitoring of target variances, and the extent that evaluations are based on target achievement. These attributes do not appear to be driven by a higher order latent construct, but are rather defining components of the construct, indicating a formative measurement model.

Measure diversity is assessed by asking respondents to indicate the extent that measures relating to six performance categories are used to evaluate subordinate performance. Categories are based on those applied in prior studies of measure diversity and performance measurement (Ittner et al., 2003; Scott \& Tiessen, 1999; Henri, 2006b). As performance dimensions are not necessarily related the construct is treated formatively.

Incentive pay is measured using an existing instrument from Chalos and O'Connor (2004). Their three item reflective scale is a modified version of the construct developed by Shields and Young (1993). Factor analysis returns a single factor with item loadings $>0.66$ and satisfactory reliability (Var. 65.7\%, $\alpha=0.73$ ).

Incentive determination is assessed using a single item based on the measure used by Simons (1987) and the definitions of Govindarajan and Gupta (1985). The item is a continuum, with one end anchored by "determined subjectively (based on top management assessment)" and the other "determined objectively (based on pre-determined formulas or targets)".

Structure is measured across five items that reflect a continuum from mechanistic to organic (Burns \& Stalker, 1961). Items are derived from Chenhall and Morris (1995), Covin et al. (2001) and Leifer and Huber (1977). All items load significantly (>0.60) on a single factor (Var. 52.7\%, $\alpha=0.77$ ).

Input control is elicited using four items adapted from Snell (1992) that ask respondents about characteristics of selection and training procedures including the emphasis placed on using

\footnotetext{
11 In the survey instrument budgeting is defined as the preparation of budgets, variance analyses and the forecasting of financials. Performance measurement systems are defined as including both financial and nonfinancial indicators that measure multiple dimensions of performance (Bisbe \& Otley, 2004).
} 
these processes to reinforce firm values and objectives. Factor analysis returns a single factor with item loadings $>0.59$ (Var. 62\%, $\alpha=0.79$ ).

$M C$ effectiveness is a purpose developed construct as no adequate instrument is available in the literature. Measurement is based on the definition of Otley and Berry (1980) who indicate that $M C$ is concerned with three main functions - goal alignment, adaptability, and integration. An initial pool of 16 items was developed based on MC literature (Emmanuel et al., 1990; Galbraith, 1973; Kloot, 1997; Lawrence \& Lorsch, 1967; Simons, 1995). The initial item pool was subject to pilot testing with practitioners and academics. Particular attention was given to the interpretation and meaning of each item. The general theme that emerged from pilot testing was that many of the items had little substantive difference (e.g. items related to coordination, integration and collaboration). The item pool was subsequently reduced to five items that retain sufficient conceptual coverage of the MC functions. As firms across strategic contexts are expected to have different control requirements, respondents were asked to indicate the importance of each MC function as well as how effective their MC package is in relation to achieving each function. A single composite measure of $\mathrm{MC}$ effectiveness is obtained by weighting the effectiveness score by its relative importance. ${ }^{12}$ As this construct is purpose developed for this study an additional check for criterion validity is conducted. MC effectiveness is correlated with two additional items, (1) overall effectiveness of $M C$, and (2) firm performance relative to competitors. Significant correlations of 0.65 and 0.31 respectively $(p<0.01)$ provide additional validation.

Strategy is based on the Miles and Snow (1978) strategic types. For the data analyses the sample is split into strategic groups using a self-typing method. An unlabelled description of each strategic type was provided to the respondent, requiring them to select the paragraph that best depicts their firm. This study uses the instrument developed by Shortell and Zajac (1990). Minor changes to the descriptors are required as the initial instrument is tailored to hospital administration. From the sample of 400 firms, 65 (16.25\%) identified themselves as defenders, 112 (28.0\%) as prospectors, $188(47.0 \%)$ as analyzers, and 35 (8.75\%) as reactors. Only firms designated as defenders and prospectors are included in the analyses.

\subsubsection{Data analysis}

Researchers investigating MC practices as a package typically use either cluster analysis (e.g. Chenhall \& Langfield-Smith, 1998; Gerdin, 2005; King \& Clarkson, 2015; Moores \& Yuen, 2001) or profile deviation analysis (e.g. Govindarajan, 1988; Selto et al., 1995). More recently researchers in organizational literature have started applying a set-theoretic method termed qualitative comparative analysis (QCA). While QCA was originally developed as a way of drawing inferences from a small number of cases, the method is increasingly applied for theory building and testing using much larger archival and survey-based datasets (Fiss, 2011; Greckhamer et al., 2013). ${ }^{13}$ In this study QCA is used to explore the first research question as it has a number of advantages over methods more common to the literature (Fiss, 2007; Ragin, 2008). First, unlike cluster analysis which lacks a test statistic to indicate the significance of a cluster solution, QCA contains statistics for coverage (similar to an $R$-squared value) and consistency (similar to a $p$-value). Second, while neither cluster analysis nor profile deviation analysis are able to determine which practices within a combination contribute to an outcome, and which are irrelevant, QCA examines the relative importance of $\mathrm{MC}$ practices by identifying whether they are core, peripheral, or redundant (Fiss, 2011; Ragin \& Fiss, 2008).

\footnotetext{
12 This measure is analogous to the multidimensional performance instrument developed by Govindarajan (1984) that is well established in the MC-strategy literature (e.g. Bisbe \& Otley, 2004; Chenhall \& LangfieldSmith, 1998; Govindarajan \& Gupta, 1985).

${ }^{13}$ Examples of recent studies using QCA with large datasets include García-Castro et al. (2013) who analyse governance practices in 363 firms and Misangyi and Acharya (2014) who compare configurations of corporate governance of 1358 firms from the S\&P 1500.
} 
In contrast to conventional statistical methods which consider associations in terms of variables and correlations, set-theoretic methods describe associations in terms of sets and set relations, where a set refers to an attribute or combination of attributes (e.g. MC practices) and set relations are expressed in terms of logical statements (Thiem et al., 2015). The particular variant of QCA applied in this study is fuzzy set QCA (fsQCA). This method is appropriate when attributes are measured as continuous values (Ragin, 2008). The basic objective of fsQCA is to determine which sets, if any, result in an outcome of interest. This is achieved by calculating the degree of membership firms have in a particular set of attributes (i.e. a MC package) and comparing this to the degree of membership these firms have in the outcome (i.e. high MC effectiveness). The empirical application of fsQCA proceeds in three main steps. These are briefly outlined below. A more detailed description is presented in Appendix B. ${ }^{14}$

The first step is to define the degree of membership a firm has in the sets under examination. This process, known as calibration, requires the specification of threshold values for each variable. The threshold values correspond to full membership, full non-membership, and a crossover point. Using these thresholds variables are rescaled from raw scores to fuzzy set membership values between 0 (full non-membership) and 1 (full membership). ${ }^{15}$ The set memberships of most MC practices are calibrated with the endpoints of the scale (i.e. raw scores of 1 and 7) corresponding to full non-membership and full membership respectively, and scale midpoints (i.e. a raw score of 4) corresponding to the crossover point. For instance, the higher the raw score on the measure for incentive determination, the greater the membership a firm has in the set corresponding to objective determination, and conversely, the lower the membership it has in the set corresponding to subjective determination.

The two exceptions are diagnostic control and interactive control uses of accounting. Using the scale endpoints are not meaningful for diagnostic control as the mean (5.51) and standard deviation (0.83) indicate that almost all firms in the sample place a high emphasis on diagnostic control, with few firms below the scale midpoint. Given this, an empirically more meaningful distinction is to represent set membership in diagnostic control as either "very high" or "not very high" (as opposed to "very high" and "very low"). Membership in the set of firms with very high diagnostic control is coded as fully in for a raw score of 7 and fully out for a raw score of 4 . The crossover is the midpoint of 5.5. To enable comparison interactive control is calibrated with the same threshold values.

For the outcome variable (MC effectiveness) this study follows recent literature and codes firms as having high MC effectiveness if they have raw scores in the $75^{\text {th }}$ percentile or higher (Erkens \& Van der Stede, 2015; Fiss, 2011). For each strategy group, firms in the bottom $25^{\text {th }}$ percentile are coded as having low MC effectiveness, with the median set as the crossover point. ${ }^{16}$

The second step is to translate the data into what is called a truth table. Truth table rows represent all possible combinations of MC practices (i.e. MC packages). As MC packages are expected to vary by strategic context separate truth tables are constructed for defender and prospector groups. In a truth table each firm is allocated to a single row based on their fuzzy set membership scores in MC practices. Once firms are allocated the truth table assesses which combinations consistently lead to the outcome of interest and which do not. This requires specification of minimum frequency and consistency thresholds. Frequency refers to the number of firms that need to be observed in a truth table row to be considered valid empirical evidence. To

\footnotetext{
${ }^{14}$ For more complete discussions of the method see Ragin (2008) and Schneider and Wagemann (2012).

${ }^{15}$ Variable calibration follows the direct method outlined by Ragin (2008, pp. 85-104). Using the specified thresholds variables are converted to fuzzy set scores through a logistic function. Following Fiss (2011) a constant of 0.001 is added to all calibrated values equal to 0.5 . This is necessary to prevent cases with attributes that fall on the crossover point from being dropped in the analysis.

${ }^{16}$ The analysis is also conducted with MC effectiveness calibrated at the 80th, 50th, and 20th percentiles. The results remain unchanged suggesting that the analysis is not overly sensitive to the specification of these thresholds.
} 
avoid inferences from single observations frequency is set at a minimum of two firms (Maggetti \& Levi-Faur, 2013). Consistency measures the degree to which firms sharing a given combination of MC practices also share the outcome of high MC effectiveness. Following recent literature the consistency threshold corresponds to the major break in consistency scores above the minimum recommended threshold of 0.80 (Crilly et al., 2012; Greckhamer et al., 2013; Schneider \& Wagemann, 2012). This approach results in a consistency threshold of 0.83 for both defender and prospector groups.

The final step involves applying an algorithm based on Boolean algebra to determine the commonalities among MC packages that consistently achieve high MC effectiveness. This leads to $M C$ practices being identified as either core, peripheral, or redundant. Theoretically core practices are those that are tightly integrated and connected to other practices. These are surrounded by peripheral practices that support the core but are loosely coupled to each other (Grandori \& Furnari, 2008; Siggelkow, 2002). Redundant practices are nonessential as whether they are present or absent has no effect on the achievement of the outcome. Fiss (2011) builds on these insights to define core practices as those "for which the evidence indicates a strong causal relationship with the outcome" and peripheral practices as "those for which the evidence for a causal relationship with the outcome is weaker" (p. 398). This emphasizes the relative importance of practices within a combination. While core practices are necessary parts of a combination to achieve an outcome, they may not be sufficient by themselves unless combined with certain peripheral practices. But as peripheral practices are weakly connected, firms are able to substitute or interchange these, resulting in multiple combinations that are potentially equally effective.

The results that follow are presented using generally accepted notation where solid circles $(\bullet)$ refer to the presence of a MC practice and circles with a cross $(\otimes)$ designate its absence (Ragin \& Fiss, 2008). The meaning of presence and absence depends on how each construct is calibrated. Where a construct is measured as a continuum, presence and absence refer to the conceptual endpoints. For example, presence $(\bullet)$ for structure refers to the use of organic structural controls while absence $(\otimes)$ refers to the use of mechanistic structural controls. For most constructs presence and absence refers to high and low use of the MC practice. Core MC practices, for which the evidence indicates a strong association with MC effectiveness, are represented by large circles whereas peripheral MC practices, which have weaker empirical support, are denoted by small circles (Fiss, 2011). Blank spaces indicate redundant MC practices as the outcome is unaffected by its presence or absence. Also reported are measures for consistency and coverage. Consistency indicates the degree to which firms share the outcome of high MC effectiveness. Coverage assesses the degree to which firms sharing the outcome are accounted for by a given MC package and the overall solution. ${ }^{17}$

\subsection{Results of fsQCA}

The fsQCA results for defender and prospector firms are displayed in Table 4. Two effective $M C$ packages are observed for defender firms. In MC package 1a the core MC practices of a diagnostic control use of accounting and mechanistic structural controls are combined with the peripheral MC practices of tight accounting controls, objective incentive determination and an absence of a very high interactive control use of accounting. MC package $1 \mathrm{~b}$ differs from $1 \mathrm{a}$ in that tight accounting controls and mechanistic structural controls are redundant $\mathrm{MC}$ practices, while measure diversity is a core $M C$ practice. The difference in core $M C$ practices suggests that $1 \mathrm{a}$ and $1 \mathrm{~b}$ are quite distinct approaches to achieving effective control in a defender strategic context. The pattern of MC practices in 1a suggests a machine bureaucratic MC package (Bedford \& Malmi, 2015; Mintzberg, 1979; Speklé, 2001) which is consistent with the general expectations in the literature for defender firms (see Table 1). In MC package $1 b$ the focus on a wider array of performance

\footnotetext{
${ }^{17}$ Coverage is separated into raw and unique portions. Raw coverage indicates the percentage of all firms sharing the outcome that are accounted for by each MC package. As some firms may be covered by more than one $\mathrm{MC}$ package in the solution, unique coverage corresponds to firms not covered by any other MC package.
} 
dimensions may necessitate a greater degree of autonomy and informal communication implying that mechanistic structural controls are not necessary for this package to be effective.

\section{$<$ Insert Table 4 about here $>$}

The fsQCA results for prospectors reveal three effective $M C$ packages. Each $M C$ package contains the same core $\mathrm{MC}$ practices of an interactive control use of accounting and organic structural controls. The presence of input controls as a peripheral practice and the redundancy of a diagnostic control use of accounting are also observed across all three MC packages. These findings are generally consistent with exploratory, devolved and adhocracy configurations discussed in prior literature (Bedford \& Malmi, 2015; Mintzberg, 1979; Speklé, 2001). Variation occurs in the presence, absence or redundancy of tightness, measure diversity, incentive pay and incentive determination. Of particular note, $\mathrm{MC}$ package $2 \mathrm{a}$ contains a loose application of accounting controls while MC package $2 \mathrm{c}$ includes a tight use. While prior literature has supported the effectiveness of one or the other, this finding suggests that both tight and loose accounting controls can be combined with other MC practices to achieve effective control outcomes in prospector firms.

Comparison of the results for defender and prospector firms indicates that how $\mathrm{MC}$ practices combine as a package varies by strategic context. This variation is generally consistent with prior MC-strategy contingency research (Table 1). However, the results diverge from conventional contingency theory in two ways. First, all effective MC packages detected in the analysis contain redundant $\mathrm{MC}$ practices. Furthermore, many of the redundant $\mathrm{MC}$ practices are shown in prior literature to have incremental performance benefits when examined in isolation. For example, the analysis of prospector firms shows that incentive pay is redundant in package 2a while measure diversity is redundant in package $2 \mathrm{c}$. This suggests that finding that a MC practice has incremental benefits in isolation does not imply that the MC practice is always necessary for a firm to achieve effective control outcomes. Second, in revealing that there are multiple, equally effective ways by which MC practices can be combined to achieve control outcomes in the same strategic context provides empirical support for the presence of equifinality.

\section{Analysis of MC systems}

The results of the previous section reveal MC packages that consistently achieve high MC effectiveness in defender and prospector strategic contexts. In this section these results are used to inform the analysis of MC systems. MC systems occur when MC practices are interdependent, meaning that the benefits from one MC practice depend on the use of another (Grabner \& Moers, 2013; Milgrom \& Roberts, 1995). The type of interdependence between MC practices may be one of either complements or substitutes. MC practices are complements when the benefits of one MC practice increase with the use of some other MC practice, whereas they are substitutes when the benefits of one $M C$ practice decrease with the use of another.

As Grabner and Moers (2013) point out observing the presence (or absence) of MC practices in a package does not mean that those practices must be interdependent (e.g. all MC practices in a package may be independently related to the outcome). An analysis of $\mathrm{MC}$ packages can, however, point to those MC practices that are more (or less) likely to be interdependent. These potential relations can be identified by examining variation in $M C$ practices within and between effective $M C$ packages. The distinction between core and peripheral MC practices is important here. As core MC practices are assumed to be more tightly connected to each other than peripheral MC practices, it is core MC practices that are most likely to exhibit interdependence (Fiss, 2011). Observing multiple core $M C$ practices within a package is suggestive of practices that act as complements as the fsQCA results indicate they are jointly required for the package to achieve high $\mathrm{MC}$ effectiveness. Observing variation in core $\mathrm{MC}$ practices between packages in the same strategic context is indicative of a substitutable relationship, as the presence of only one or the other is required for the outcome to be 
achieved. ${ }^{18}$ Based on these guidelines hypotheses are developed regarding interdependencies between $\mathrm{MC}$ practices that are expected to occur in defender and prospector strategic contexts. Given the limited theory on interdependencies between MC practices and the difficulty in interpreting higher-order interactions (Hartmann \& Moers, 1999), hypothesis development is restricted to pairwise associations.

\subsection{Hypothesis development}

$M C$ packages $1 \mathrm{a}$ and $1 \mathrm{~b}$ each contain two core $\mathrm{MC}$ practices. In package $1 \mathrm{a}$, the two core $\mathrm{MC}$ practices are mechanistic structural controls and the diagnostic control use of accounting. Mechanistic structures, characterized by vertical chains of command, centralized authority, and formal channels of communication, increase the effectiveness of defenders by focusing attention towards resource utilization and efficiency (Langfield-Smith, 2008; Miles \& Snow, 1978). Diagnostic controls reinforce mechanistic structural controls by establishing accountability for specific dimensions of performance (Henri, 2006a). Furthermore, exception based monitoring allows top managers to identify performance concerns and efficiently allocate attention without the need to engage in more costly forms of communication with subordinates (Widener, 2007). The benefits from diagnostic control also increase with the use of mechanistic structural controls as the standardization and specialization of tasks makes the efforts of subordinates more amenable to quantification (Hirst, 1983). Formally the following is expected:

H1. Diagnostic control use of accounting and mechanistic structural controls are complements in defender firms.

The core MC practices in MC package $1 \mathrm{~b}$ are diagnostic control use of accounting and measure diversity. Although firms following defender-type strategies are typically associated with measures that emphasize cost control (Chenhall, 2003), Dent (1990) argues that a narrow focus on cost metrics may not maximize efficiency in these firms. Rather control is more effectively achieved through a broader focus on non-financial dimensions of performance such as quality and operational processes (Kaplan, 1983). As these broader scope measures (e.g. defect rates, on-time delivery, machine utilization) are more closely related to the controllable activities of subordinates, feedback on actual performance against predetermined targets enables more timely and effective adjustments to actions or plans when results deviate from expectations (Ittner \& Larcker, 1997). As defender firms operate in stable environments and tend to conduct routine tasks (Miles \& Snow, 1978) quantitative measures are relatively reliable indicators of subordinate actions (Fisher \& Govindarajan, 1993). This suggests that higher measure diversity will increase the benefits from using accounting for diagnostic control in defender firms. Using accounting diagnostically is also expected to increase the returns from greater measure diversity by directing subordinate attention towards those dimensions important for improving task performance (Flamholtz, 1983). Thus the following hypothesis is posited:

H2. Diagnostic control use of accounting and measure diversity are complements in defender firms.

The core $\mathrm{MC}$ practices of measure diversity and mechanistic structural controls are found to vary between $\mathrm{MC}$ packages $1 \mathrm{a}$ and $1 \mathrm{~b}$. This finding suggests they are substitutes, that is, an

\footnotetext{
${ }^{18}$ Configuration theory suggests that as peripheral practices are assumed to be weakly connected to each other they are more easily interchangeable (Fiss, 2011). However, this does not mean that peripheral practices that can replace each other will exhibit interdependence. That is, the practices may have similar functional effects in achieving the outcome, making them exchangeable parts of the overall configuration, but they are not necessarily counterproductive. We thank an anonymous reviewer for this insight.
} 
increased use of one reduces the effectiveness of the other, and vice-versa. ${ }^{19}$ Broad-scope measures increase the complexity of the performance information provided to top managers (Lipe \& Salterio, 2000). Developing a shared understanding of the meaning and implications of complex information requires more interpersonal and intensive forms of communication (Daft \& Lengel, 1986; Hall, 2010). However, mechanistic structural controls emphasize structured and restricted flows of information (Burns \& Stalker, 1961; Henri, 2006b). Formal, impersonal and codified forms of information exchange are unable to transfer the tacit and specific knowledge required to understand the connections between a diverse set of performance measures (Ittner et al., 2003). Mechanistic structural controls will therefore reduce the effectiveness of broad-scope information. A performance measurement system with high measure diversity may also undermine mechanistic control structures which are premised on predictability and conformity. An increase in the variety of performance measures can produce conflicting signals (Lillis \& van Veen-Dirks, 2008) and encourage divergence from planned behaviours (Henri, 2006b). These arguments lead to the following hypothesis:

H3. Mechanistic structural controls and measure diversity are substitutes in defender firms.

The results for prospector firms in Table 4 reveal three effective MC packages each with the same jointly observed core $\mathrm{MC}$ practices: organic structural controls and an interactive control use of accounting. Organic structural controls are effective in prospector firms as the lack of standardization, dispersed authority, lateral communication and free flow of information encourage autonomous experimentation and opportunity search that are necessary to generate innovation (Burgelman, 1991; Burns \& Stalker, 1961). However, for emerging opportunities to result in improved firm outcomes they need to be translated into the strategic agenda of the firm. An interactive control use of accounting increases the benefits of organic structural controls as through frequent dialogue with subordinates managers are able to identify, and focus resources towards, those opportunities with the most potential and direct attention away from emerging initiatives that are not aligned with firm objectives (Henri, 2006a; Simons, 1995). Organic structural controls complement interactive controls as subordinates are provided the necessary flexibility to quickly adapt to strategic uncertainties that become known through discussions with managers. These expectations are formalised as follows:

H4. Interactive control use of accounting and organic structural controls are complements in prospector firms.

\subsection{Research method}

The empirical analysis of MC systems follows the approach of Grabner and Moers (2013) for estimating the production function of interdependent $M C$ practices. The production function examines whether MC practices are more or less beneficial for a firm when adopted in combination. The production function is analysed, as opposed to the demand function, as this study focuses on the consequences of the choice of MC practices on control outcomes. This focus is appropriate as the control problems examined in this study (i.e. the alignment of behaviours to the strategic objectives of the firm) are complex and require significant experimentation by top management, particularly in conditions characterized by uncertainty such as the prospector strategic context (Simons, 1995). Hence it is unlikely that firms will be, on average, in an optimal equilibrium.

\footnotetext{
${ }^{19}$ An alternative interpretation of the fsQCA results is that mechanistic structural controls and measure diversity are substitutes in complementing a diagnostic control use of accounting. This suggests a three-way interaction. While hypothesis development is limited to pairwise associations, the possibility of a higher-order interaction is empirically examined. No support for a three-way interaction is found. We thank an anonymous reviewer for this observation.
} 
To test for interdependence the MC practices and hypothesized interactions are regressed on MC effectiveness separately for defender $(n=65)$ and prospector $(n=112)$ firms. The sample and construct measures used in the analysis of $M C$ systems are the same as described in Section 2.2. To adequately capture interdependence between $M C$ practices it is also necessary to account for the joint variance in MC practices attributable to contextual factors (Grabner \& Moers, 2013). Apart from strategy the main determinants of the $M C$ practices in this study relate to dimensions of the task environment (Chenhall, 2003; Langfield-Smith, 2008). This is controlled for by including interaction terms between hypothesized MC practices and a variable that captures environmental dynamism $(E N V D Y N)$. Environmental dynamism refers to the level of unpredictability and turbulence in the task environment (Miller \& Friesen, 1983). Environmental dynamism is treated as a formative construct and is measured by asking respondents to indicate the rate of change and the degree of predictably across five dimensions (Gordon \& Narayanan, 1984). The items used are detailed in Appendix A.

All independent variables are mean-centred prior to the construction of the interaction terms (Cohen et al., 2003). The variance inflation factors for all models are well below the general threshold of 10 indicating that multicollinearity is not a significant concern (Hair et al., 2006).

\subsection{Results of regression analyses}

Table 5 reports the regression results for the defender sample. Models 1 to 3 examine the hypotheses independently while Model 4 includes all hypothesized interaction terms. $\mathrm{H} 1$ predicts that the diagnostic control use of accounting and mechanistic structural controls are complements in defender firms. The interaction term between DIAG and STRUCT is negative and significant in Model $1(p<0.10)$ and Model $4(p<0.01)$. This provides support for $\mathrm{H} 1$ as higher diagnostic control use of accounting combined with less organic (more mechanistic) structural controls are associated with an increase in $\mathrm{MC}$ effectiveness. $\mathrm{H} 2$ posits a complementary association between diagnostic control use of accounting and measure diversity. The interaction term between DIAG and MEAS in both Model 2 and Model 4 is insignificant. $\mathrm{H} 2$ is not supported. $\mathrm{H} 3$ postulates that measure diversity and mechanistic structural controls are substitutes. The interaction between MEAS and STRUCT is insignificant in Model 3, however, once controlling for all hypothesized interactions in Model 4, the term is positive and significant $(p<0.05) .{ }^{20}$ This provides support for $\mathrm{H} 3$ as higher (lower) measure diversity decreases (increases) the effectiveness of mechanistic structural controls.

$<$ Insert Table 5 about here $>$

As a robustness test the peripheral MC practices from the fsQCA results reported in Table 4 that provide consistent but weaker support for interdependence are included in the analysis. From Table 4 it is observed that incentive determination is a common MC practice to both MC packages, indicating weak support for a complementary association with a diagnostic control use of accounting. To assess this possibility, interactions with INCDET are included in Model 5. All of the additional interactions are found to be insignificant, while DIAG*STRUCT and MEAS*STRUCT interactions remain significant $(p<0.05)$. Overall, $\mathrm{H} 1$ and $\mathrm{H} 3$ are supported, while $\mathrm{H} 2$ is rejected.

\footnotetext{
${ }^{20} \mathrm{An}$ additional consideration is whether observed interdependencies are a characteristic common to all firms or whether they are conditional on firm context (Cassiman \& Veugelers, 2006; Grabner \& Moers, 2013). To test whether interdependencies are conditional on strategic context the interaction between DIAG and STRUCT and the interaction between MEAS and STRUCT are compared to the regression coefficients of the same model conducted on the prospector sample. A significant difference is found in comparison to prospectors for DIAG*STRUCT $(p<0.01)$ but not for MEAS*STRUCT. These results imply that the interdependence between a diagnostic control use of accounting and mechanistic structural controls is conditional on strategic context, while the interdependence between measure diversity and structural controls may not be limited to defender firms.
} 
Results for the prospector group are presented in Table 6. Model 1 examines $\mathrm{H} 4$ which states that an interactive control use of accounting and organic structural controls are complements in prospector firms. $\mathrm{H} 4$ is supported with a positive and significant effect found for the interaction between INT and STRUCT $(p<0.01) .{ }^{21}$ As a robustness test the MC practices with weaker evidence for interdependence from the fsQCA results reported in Table 4 are added to the regression model. Input controls (INPUT) are included as these are observed in all effective MC packages, which provides weak evidence of a complementary effect with other consistently observed MC practices. Tightness of accounting controls (TIGHT) and incentive determination (INCDET) are included as these MC practices vary between MC packages providing weak evidence of a substitution effect. Model 2 (Table 6) includes the interactions between INT, STRUCT, INPUT, TIGHT, and INCDET. Results provide additional support for $\mathrm{H} 4$ with the term INT*STRUCT positive and significant $(p<0.05)$. None of the other interaction terms are found to be significantly associated with $M C$ effectiveness except for the positive interaction between INT and TIGHT $(p<0.10)$. This suggests that tight accounting controls need to be combined with an interactive control use of accounting to be effective in prospector firms. However, as the association is not consistently observed across all effective MC packages in the fsQCA results of Table 4, and given the marginal significance of the regression term, the overall evidence for interdependence between INT and TIGHT is weak at best.

\section{Discussion and conclusion}

The purpose of this study is to investigate combinations of MC practices that are effective in different strategic contexts. Specifically, this study examines the MC packages that are effective in defender and prospector strategic contexts and the systems of MC practices that occur within these packages. The findings of this study contribute to understanding the association between $\mathrm{MC}$ and strategy, and $\mathrm{MC}$ combinations more generally, in a number of ways.

First, this study shows that not all MC practices observed to be individually associated with firm benefits are necessarily relevant for achieving effective control outcomes when examined as part of a MC package. For instance, prior studies find that firms following prospector-type strategies are associated with greater firm benefits when they have higher performance measure diversity (Chenhall \& Langfield-Smith, 1998; Van der Stede et al., 2006), place more weight on performancebased pay (Balkin \& Gomez-Mejia, 1990; Boyd \& Salamin, 2001), and incorporate greater subjectivity in the determination of incentive compensation (Govindarajan \& Fisher, 1990; Govindarajan \& Gupta, 1985). These results are consistent with some of the prospector MC packages observed in this study while in other packages the MC practices are found to be redundant, that is, the presence or absence of the $\mathrm{MC}$ practice is not associated with achievement of the outcome. Thus finding an association between an $M C$ practice and an outcome in isolation does not imply that the MC practice is always needed to achieve effective control as firms are able to combine MC practices within a package in different ways (Gerdin, 2005).

Second, this study provides empirical evidence for the presence of equifinality in MC combinations (Erkens \& Van der Stede, 2015; Gerdin, 2005; Sandelin, 2008). Most contingencybased research assumes a direct relationship between context and $M C$ practices ignoring the possibility that "there may be a range of viable responses to specific contingencies" (Dent, 1990, p. 10). It is found that for firms operating in defender and prospector strategic contexts there are multiple MC packages that are equally effective. It should be noted that these findings do not mean

\footnotetext{
${ }^{21}$ The coefficient of the interaction between INT and STRUCT for prospector firms is compared with the coefficients for the same regression conducted on defender firms. Tests reveal a significant difference $(p<$ $0.10)$ implying that the interdependence between the interactive control use of accounting and organic structural controls is conditional on the strategic context of the firm.
} 
that conventional contingency analyses are invalid - in fact, most of the $M C$ practices within effective $M C$ packages, and the $M C$ practice variations between strategic contexts, observed in this study are consistent with prior research. What the results do emphasize is that MC practice choices are not entirely determined by the strategic context of the firm; rather these conditions limit or constrain the availability of viable alternatives. As such conventional contingency approaches are unlikely to reveal the full range of effective MC combinations adopted by firms in a particular context.

Third, this study examines interdependencies between MC practices and how these vary depending on the strategic context of the firm. Evidence from the analysis of both MC packages and MC systems indicate that defender firms have more effective control outcomes when they combine mechanistic structural controls with a diagnostic control use of accounting, while prospector firms benefit more when they combine organic structural controls and an interactive control use of accounting. This latter result differs from Chenhall and Morris (1995) who report that entrepreneurial firms are more effective when they combine an organic structure with tight accounting controls. This study suggests it is the choice to use accounting interactively, rather than the degree of tightness, that is interdependent with the choice of structural controls. Mechanistic structural controls and measure diversity are also observed to act as substitutes in defender firms. The result implies that defender firms emphasizing mechanistic control structures will have less effective $\mathrm{MC}$ if they implement broad scope performance measurement systems without making adjustments to structural controls.

The results of the $\mathrm{MC}$ systems analysis also contribute to the economics-based accounting literature on organizational design choices (e.g. Abernethy et al., 2004; Indjejikian \& Matějka, 2012; Moers, 2006; Nagar, 2002). This literature examines accounting control choices in terms of the selection and properties of performance measures and their inclusion in incentive contracts, but has not considered variations in the use of performance measures for control. The findings of this study indicate that the choice to use performance measures diagnostically or interactively is an important consideration that could be incorporated into organizational design frameworks (e.g. Brickley et al., 1997). The findings further suggest that structural design choices associated with mechanistic and organic structures, other than delegation, may also be co-determined (e.g. standardization, specialization, integrative mechanisms, information access). Additionally, this study emphasizes that interdependencies between organizational design variables should not be assumed to be applicable to all firms. Instead the extent of interdependence is likely to be influenced by the operating environment of the firm (Grabner \& Moers, 2013).

Fourth, this study demonstrates how an understanding of $M C$ packages can inform the analysis of MC systems. This is somewhat in contrast to Grabner and Moers (2013) who argue that the $M C$ package perspective is ill-suited as a starting point for examining interdependencies between $\mathrm{MC}$ practices. One reason for this position is that the methods commonly used to investigate MC practices in combination, such as cluster analysis and profile deviation analysis, provide limited insight into the inner workings of a package. The method used in this study, fsQCA, is able to determine the relevance of $\mathrm{MC}$ practices within a package by distinguishing between core, peripheral and redundant practices. While the analysis of $\mathrm{MC}$ packages cannot confirm interdependence, developing an understanding of the relevance of $\mathrm{MC}$ practices within a package can facilitate $\mathrm{MC}$ theory development by indicating which are likely to be interrelated and the nature of those relationships. This would be particularly useful for MC literature as there is currently little theoretical guidance as to which of a myriad of MC practices might be interdependent in any given setting.

Finally, in examining packages and systems this study reveals that a MC package is composed of both independent and interdependent MC practices. In fact, the results insinuate that the assumed extent of interdependence between MC practices in the literature may well be overstated (Grabner \& Moers, 2013; Indjejikian \& Matějka, 2012). Rather the effectiveness of most MC practices within a package appears to be primarily attributable to their fit with context rather 
than with each other. There are a number of caveats to this contention. One concerns the sample size, which although comparable to other survey-based studies, may be inadequate to capture the interaction effects of multiple MC practices. Another is the set of MC practices examined. The inclusion of $\mathrm{MC}$ practices in this study is guided by prior empirical findings. However, there are numerous other MC practices evident in normative frameworks (e.g. Ferreira \& Otley, 2009; Malmi \& Brown, 2008) that may have systematic associations with those considered in this study. The level of aggregation could also be an issue. Gaining a deeper understanding of interdependence between MC practices may require an analysis of more specific attributes (Friis et al., 2014; Grabner \& Moers, 2013). For example, this study uses a single measure for the method of incentive determination, yet managers can incorporate subjectivity in a number of ways: subjective weightings on objective measures, use of discretionary bonuses, subjective evaluations of qualitative task dimensions, or subjective evaluations of non-task related dimensions (Gibbs et al., 2004; Grabner, 2014; Höppe \& Moers, 2011). The use of finer-grained constructs may be better able to reveal MC practice interdependencies.

Another limitation of this study is the reliance on data obtained from the subjective assessments of managers. While significant attention was given to survey development, pre-testing, and assessment of construct validity, the measures may still contain noise. Furthermore, while diagnostic tests suggest that non-response and single-source biases are not significant concerns, this cannot be entirely ruled out. The typical caveats to generalizability also apply. In particular, certain firm types, such as multi-divisional firms, were not included in the sample of this study. A final qualification is that while this study reveals more than one way to achieve high MC effectiveness in a given strategic context, this does not imply that firms have unrestricted agency in selecting the MC practices that constitute an effective MC package or that these choices are without causal antecedents. Although the Miles and Snow (1978) categorization is associated with factors such as environmental dynamism and technological routineness, there may be other contextual dimensions that affect the relative costs and benefits of combinations of MC practices across firms. Future research could extend this study by examining if and how other contextual factors affect the range of viable MC packages, the degree of interdependence between $M C$ practices within a package, and the reasons why a firm is observed with a particular $\mathrm{MC}$ combination when there are viable alternatives (e.g. path dependence, managerial preferences). Despite these limitations, this study contributes to the limited body of research examining how and why MC practices combine and the strategic contexts in which particular MC combinations are effective. 


\section{References}

Abernethy, M. A., Bouwens J., \& van Lent, L. (2004). Determinants of control system design in divisionalized firms. The Accounting Review, 79, 545-570.

Abernethy, M. A., \& Brownell, P. (1999). The role of budgets in organisations facing strategic change: an exploratory study. Accounting, Organizations and Society, 24(3), 189-204.

Abernethy, M. A., Dekker, H. C., \& Schulz, A. K-D. (2015). Are employee selection and incentive contracts complements or substitutes? Journal of Accounting Research, 43(4), 633-668.

Ahrens, T., \& Chapman, C. S. (2004). Accounting for flexibility and efficiency: A field study of management control systems in a restaurant chain. Contemporary Accounting Research, 21(2), 271-301.

Auzair, S. M., \& Langfield-Smith, K. (2005). The effect of service process type, business strategy and life cycle stage on bureaucratic MCS in service organizations, Management Accounting Research, 16(4), 399421.

Balkin, D. B., \& Gomez-Mejia, L. R. (1990). Matching compensation and organizational strategies. Strategic Management Journal, 11(2), 153-169.

Barki, H., \& Pinsonneault, A. (2005). A Model of Organizational Integration, Implementation Effort, and Performance. Organization Science, 16(2), 165-179.

Bedford, D. S. (2015). Management control systems across different modes of innovation: Implications for firm performance. Management Accounting Research, 28, 12-30.

Bedford, D. S., \& Malmi, T. (2015). Configurations of control: an exploratory analysis. Management Accounting Research, 27, 2-26.

Bedford, D. S., \& Sandelin, M. (2015). Investigating management control configurations using qualitative comparative analysis: an overview and guidelines for application. Journal of Management Control, 26, 5-26.

Bisbe, J., \& Otley, D. (2004). The effects of the interactive use of management control systems on product innovation. Accounting, Organizations and Society, 29(8), 709-737.

Bisbe, J., Batista-Foguet, H-M., \& Chenhall, R. (2007). Defining management accounting constructs: A methodological note on the risks of conceptual misspecification. Accounting, Organizations and Society, 32(7-8), 789-820.

Boyd, B. K., \& Salamin, A. (2001). Strategic reward systems: A contingency model of pay system design. Strategic Management Journal, 22, 777-792.

Brickley, J. A., Smith, C. W., \& Zimmerman, J. L. (1997). Managerial Economics and Organizational Architecture. Burr Ridge, IL: Irwin.

Burgelman, R. A., (1991). Intraorganizational ecology of strategy making and organizational adaptation: theory and field research. Organization Science, 2, 239-262.

Burns, T., \& Stalker, G. (1961). The Management of Innovation. London: Tavistock.

Campbell, D. (2012). Employee selection as a control system. Journal of Accounting Research, 50(4), 931-966.

Cassiman, B., \& Veugelers, R. (2006). In search of complementarity in innovation strategy: internal R\&D and external knowledge acquisition. Management Science, 52(1), 68-82.

Chalos, P., \& O'Connor, N. G. (2004). Determinants of the use of various control mechanisms in US-Chinese joint ventures. Accounting Organizations and Society, 29(7), 591-608.

Chapman, C. S. (1997). Reflections on a contingent view of accounting. Accounting, Organizations and Society, 22(2), 189-205.

Chenhall, R. H. (2003). Management control systems design within its organisational context: findings from contingency-based research and directions for the future. Accounting, Organizations and Society, 28(2-3), 127-168.

Chenhall, R. H. (2005). Integrative strategic performance measurement systems, strategic alignment of manufacturing, learning and strategic outcomes: an exploratory study. Accounting Organizations and Society, 30(5), 395-422.

Chenhall, R. H., \& Langfield-Smith, K. (1998). The relationship between strategic priorities, management techniques and management accounting: an empirical investigation using a systems approach. Accounting, Organizations and Society, 23(3), 243-264.

Chenhall, R. H., \& Moers, F. (2015). The role of innovation in the evolution of management accounting and its integration into management control. Accounting, Organizations and Society, 47, 1-13.

Chenhall, R. H., \& Morris, D. (1995). Organic decision and communication processes and management accounting systems in entrepreneurial and conservative business organisations. Omega, 35(5), 485497. 
Cohen, J., Cohen, P., West, S., \& Aiken, L., (2003). Applied Multiple Regression / Correlation Analysis for the Behavioural Sciences, $3^{\text {rd }}$ Edition. New Jersey: L. Erlbaum Associates.

Cooper, B., \& Glaesser, J. (2011). Paradoxes and pitfalls in using fuzzy set QCA: Illustrations from a critical review of a study of educational inequality. Sociological Research Online, 16(3), 8.

Covin, J. G., Slevin, D. P., \& Heeley, M. B. (2001). Strategic decision making in an intuitive vs. technocratic mode: Structural and environmental considerations. Journal of Business Research, 52, 51-67.

Crilly, D., Zollo, M., \& Hansen, M. T. (2012). Faking it or muddling through? Understanding decoupling in response to stakeholder pressures. Academy of Management Journal, 55(6), 1429-1448.

Daft, R. L., \& Lengel, R. H. (1986). Organizational information requirements, media richness and structural design. Management Science, 32(5), 554-571.

Davila, T. (2000). An empirical study on the drivers of management control systems' design in new product development. Accounting, Organizations and Society, 25(4-5), 383-409.

Dekker, H. C., Groot, T. L. C. M., \& Schoute, M. (2013). A balancing act? The implications of mixed strategies for performance measurement system design. Journal of Management Accounting Research, 25, 71-98.

Dent, J. F. (1990). Strategy, organisation and control: Some possibilities for accounting research. Accounting, Organisations and Society, 15(1-2), 3-25.

Desarbo, W. S., Di Benedetto, C. A., Song, M., \& Sinha, I. (2005). Revisiting the Miles and Snow strategic framework: Uncovering relationships between strategic types, capabilities, environmental uncertainty, and firm performance. Strategic Management Journal, 26, 47-74.

Dillman, D. A. (2000). Mail and Internet Surveys: The Tailored Design Method. Canada: John Wiley \& Sons.

Donaldson, L. (2001). The Contingency Theory of Organizations. London: Sage Publications.

Duncan, R. B. (1973). Multiple decision-making structures in adapting to environmental uncertainty: the impact on organizational effectiveness. Human Relations, 26(3), 273-291.

Emmanuel, C. R., Otley, D. T., \& Merchant, K. (1990). Accounting for Management Control. New York: Chapman and Hall.

Erkens, D. H., \& Van der Stede, W. A. (2015). Strategy and control: Findings from a set-theoretical analysis of high-performance manufacturing firms. Marshall School of Business Working Paper No. ACC 03.13. Available at SSRN: http://ssrn.com/abstract=2296468 or http://dx.doi.org/10.2139/ssrn.2296468

Ferreira, A., \& Otley, D. (2009). The design and use of performance management systems: An extended framework for analysis. Management Accounting Research, 20(4), 263-282.

Fisher, J. G. (1995). Contingency-based research on management control systems: categorization by level of complexity. Journal of Accounting Literature, 14, 24-53.

Fisher, J. G., \& Govindarajan, V. (1993). Incentive compensation design, strategic business unit mission, and competitive strategy. Journal of Management Accounting Research, 5, 129-144.

Fiss, P. C. (2007). A set-theoretic approach to organizational configurations. Academy of Management Review, 32(4), 1180-1198.

Fiss, P. C. (2011). Building better causal theories: a fuzzy set approach to typologies in organization research. Academy of Management Journal, 54(2), 393-420.

Flamholtz, E. (1983). Accounting, budgeting and control systems in their organisational context: Theoretical and empirical perspectives. Accounting, Organisations and Society, 8(2-3), 153-169.

Friis, I., Hansen, A., \& Vámosi, T. (2014). On the effectiveness of incentive pay: Exploring complementarities and substitution between management control system elements in a manufacturing firm. European Accounting Review, DOI:10.1080/09638180.2014.976055.

Galbraith, J. (1973). Designing complex organisations. USA: Addison Wesley Publishing.

García-Castro, R., Aguilera, R. V., \& Ariño, M. A. (2013). Bundles of firm corporate governance practices: a fuzzy set analysis. Corporate Governance: An International Review, 21(4), 390-407.

Gerdin, J. (2005). Managing accounting system design in manufacturing departments: an empirical investigation using a multiple contingency approach. Accounting, Organizations and Society, 30(2), 99-126.

Gerdin, J., \& Greve, J. (2004). Forms of contingency fit in managerial accounting research - a critical review. Accounting, Organizations and Society, 29(3-4), 303-326.

Gibbs, M., Merchant, K. A., Van der Stede, W. A., \& Vargus, M. E. (2004). Determinants and effects of subjectivity in incentives. The Accounting Review, 79(2), 409-436.

Gordon, L. A., \& Narayanan, V. K. (1984). Management accounting systems, perceived environmental uncertainty and organization structure: an empirical investigation. Accounting, Organizations and Society, 9(1), 33-47. 
Govindarajan, V. (1984). Appropriateness of accounting data in performance evaluation: an empirical examination of environmental uncertainty as an intervening variable. Accounting Organizations and Society, 9(2), 125-135.

Govindarajan, V. (1988). A contingency approach to strategy implementation at the business-unit level: integrating administrative mechanisms with strategy. Academy of Management Journal, 31, 828-853.

Govindarajan, V., \& Fisher, J. (1990). Strategy, control systems and resource sharing: Effects on business-unit performance. Academy of Management Journal, 33, 259-285.

Govindarajan, V., \& Gupta, A.K. (1985). Linking control systems to business unit strategy: impact on performance. Accounting, Organizations and Society, 10(1), 51-66.

Grabner, I. (2014). Incentive system design in creativity-dependent firms. The Accounting Review, 89(5), 17291750

Grabner, I., \& Moers, F. (2013). Management control as a system or a package? Conceptual and empirical issues. Accounting, Organizations and Society, 38(6-7), 407-419.

Grandori, A., \& Furnari, S. (2008). A chemistry of organization: Combinatory analysis and design. Organization Studies, 2(3), 459-485.

Greckhamer, T., Misangyi, V. F., \& Fiss, P. C. (2013). The two QCAs: from a small-N to a large-N set theoretic approach. In P. C. Fiss, B. Cambre \& A. Marx (Eds.), Configurational theory and methods in organizational research. Research in the Sociology of Organizations, Volume 38, 49-75, Bingley, UK: Emerald.

Gupta, A. K. (1987). SBU strategies, corporate-SBU relations, and SBU effectiveness in strategy implementation. Academy of Management Journal, 30(3), 477-500.

Hair, J., Anderson, R., Tatham, R., \& Black, W. (2006). Multivariate Data Analysis, Sixth Edition, New Jersey: Prentice Hall.

Hall, M. (2010). Accounting information and managerial work. Accounting, Organizations and Society, 35(3), 301-315.

Hambrick, D. C. (2003). On the staying power of defenders, analyzers, and prospectors. Academy of Management Executive, 17(4). 115-118.

Hartmann, F., \& Moers, F. (1999). Testing contingency hypotheses in budgetary research: an evaluation of the use of moderated regression analysis. Accounting, Organizations and Society, 24(4), 291-315.

Henri, J-F. (2006a). Management control systems and strategy: a resource-based perspective. Accounting, Organizations and Society, 31(6), 529-558.

Henri, J-F. (2006b). Organizational culture and performance measurement systems. Accounting, Organizations and Society, 31(1), 77-103.

Hirst, M. K. (1983). Reliance on accounting performance measures, task uncertainty, and dysfunctional behaviour: some extensions. Journal of Accounting Research, 21(2), 596-605.

Höppe, F., \& Moers, F. (2011). The choice of different types of subjectivity in CEO annual bonus contracts. The Accounting Review, 86(6), 2023-2046.

Hrebiniak, L. G., \& Joyce, W. F. (1985). Organizational adaptation: Strategic choice and environmental determinism. Administrative Science Quarterly, 30, 336-349.

Indjejikian, R. J., \& Matĕjka, M. (2012). Accounting decentralization and performance evaluation of business unit managers. The Accounting Review, 87(1), 261-290.

Ittner, C. D. C., \& Larcker, D. F. D. (1997). Quality strategy, strategic control systems, and organizational performance. Accounting, Organizations and Society, 22(3-4), 293-314.

Ittner, C. D., Larcker, D. F., \& Randall, T. (2003). Performance implications of strategic performance measurement in financial services firms. Accounting, Organizations and Society, 28(7), 715-741.

Jarvis, C. B., MacKenzie, S. B., \& Podsakoff, P.M. (2003). A critical review of construct indicators and measurement model misspecification in marketing and consumer research. Journal of Consumer Research, 30, 199-218.

Kabanoff, B., \& Brown, S. (2008). Knowledge structures of prospectors, analyzers, and defenders: Content, structure, stability, and performance. Strategic Management Journal, 29, 149-171.

Kaplan, R. S. (1983). Measuring manufacturing performance: A new challenge for managerial accounting research. The Accounting Review, 58, 686-705.

King, R., \& Clarkson, P. (2015). Management control system design, ownership, and performance in professional service organisation. Accounting, Organizations and Society, 45, 24-39.

Kloot, L. (1997). Organisational learning and management control systems: Responding to environmental change. Management Accounting Research, 8, 47-73. 
Langfield-Smith, K. (2008). A review of quantitative research in management control systems and strategy. In: Chapman, C. S., Hopwood, A. G., \& Shields, M. D. (Eds), Handbook of Management Accounting Research Volume 2, 753-783. Oxford: Elsevier.

Lawrence, P. R., \& Lorsch, J. W. (1967). Organization and environment: Managing differentiation and integration. Boston: Harvard University.

Leifer, R., \& Huber, G. P. (1977). Relations among perceived environmental uncertainty, organization structure, and boundary-spanning behavior. Administrative Science Quarterly, 22, 235-247.

Lillis A. M., \& van Veen-Dirks, P. M. G. (2008). Performance measurement system design in joint strategy settings. Journal of Management Accounting Research, 20, 25-57.

Lipe, M. G., \& Salterio, S. E. (2000). The balanced scorecard: Judgmental effects of common and unique performance measures. The Accounting Review, 75(3), 283-298.

Mackie, J. L. (1965). Causes and conditions. American Philosophical Quarterly, 2(4), 245-264.

Maggetti, M., \& Levi-Faur, D. (2013). Dealing with errors in QCA. Political Research Quarterly, 66(1), $198-204$.

Malmi, T., \& Brown, D. (2008). Management control systems as a package - opportunities, challenges and research directions. Management Accounting Research, 19, 287-300.

Merchant, K. A., \& Van der Stede, W. A. (2012). Management Control Systems: Performance Measurement, Evaluation and Incentives. $3^{\text {rd }}$ Edition. London: Prentice Hall.

Merchant, K. A. (1985). Control in Business Organizations. Boston: Pitman Publishing.

Miles, R. W., \& Snow, C. C. (1978). Organizational strategy, structure and process. New York: McGraw Hill.

Miller, D. (1988), Relating Porter's business strategies to environment and structure: analysis and performance implications. Academy of Management Journal, 31(2), 280-308.

Miller, D., \& Friesen, P. H. (1982). Innovation in conservative and entrepreneurial firms: two models of strategic momentum. Strategic Management Journal, 3, 1-25.

Miller, D., \& Friesen, P. H. (1983). Strategy-making and environment: the third link. Strategic Management Journal, 4, 221-235.

Milgrom, P., \& Roberts, J. (1995). Complementarities and fit: strategy, structure, and organizational change in manufacturing. Journal of Accounting and Economics, 19 (2-3), 179-208.

Mintzberg, H. (1979). The Structure of Organizations. Upper Saddle River, New Jersey: Prentice Hall.

Misangyi, V. F., \& Acharya, A. G. (2014). Substitutes or complements? A configurational analysis of corporate governance mechanisms. Academy of Management Journal, 57(6), 1681-1705.

Moers, F. (2006). Performance measure properties and delegation. The Accounting Review, 81(4), 897-924.

Moores, K., \& Yuen, S. (2001). Management accounting systems and organizational configuration: a life-cycle perspective. Accounting, Organizations and Society, 26(4-5), 351-389.

Nagar, V. (2002). Delegation and Incentive Compensation. The Accounting Review, 77(2), 379-395.

Otley, D. (1980). The contingency theory of management accounting: Achievement and prognosis. Accounting, Organizations and Society, 5(4), 413-428.

Otley, D., \& Berry, A. (1980). Control, Organisation and Accounting. Accounting, Organizations and Society, $5(2), 231-244$

Petter, S., Straub, D., \& Rai, A. (2007). Specifying formative constructs in information systems research. MIS Quarterly, 31, 623-656.

Podsakoff, P. M., MacKenzie, S. B., Lee, J-Y., \& Podsakoff, N. P. (2003). Common method biases in behavioral research: A critical review of the literature and recommended remedies. Journal of Applied Psychology, 88(5), 879-90.

Ragin, C. C. (1997). Turning the tables: how case-oriented research challenges variable-oriented research. Comparative Social Research, 16, 27-42.

Ragin, C. C. (2008). Redesigning social inquiry: Fuzzy sets and beyond. Chicago: University of Chicago Press.

Ragin, C. C., \& Fiss, P. C. (2008). Net effects analysis versus configurational analysis: An empirical demonstration. In: Ragin, C. C. (Ed), Redesigning social inquiry: Fuzzy sets and beyond, 190-212. Chicago: University of Chicago Press.

Rihoux, B., Marx, A. (2013). QCA 25 years after "The comparative method": Mapping, challenges, and innovations. Political Research Quarterly, 66, 167-235.

Rossiter, J. R. (2002). The C-OAR-SE procedure for scale development in marketing. International Journal of Research in Marketing, 19, 305-335.

Sandelin, M. (2008). Operation of management control practices as a package - A case study on control system variety in a growth firm context. Management Accounting Research, 19(4), 324-343.

Schneider, C. Q., \& Wagemann, C. (2012). Set-theoretical methods for the social sciences: A guide to qualitative comparative analysis. Cambridge: Cambridge University Press. 
Scott, T. W., \& Tiessen, P. (1999). Performance measurement and managerial teams. Accounting, Organizations and Society, 24(3), 263-285.

Selto, F., Renner, C., \& Young, S. (1995). Assessing the organisational fit of a just-in-time manufacturing system: testing selection, interaction and systems models of contingency theory. Accounting, Organizations and Society, 20(7-8), 665-684.

Shields, M. D., \& Young, S. M. (1993). Antecedents and consequences of participative budgeting: Evidence on the effects of asymmetrical information. Journal of Management Accounting Research, 5, 266-280.

Siemsen, E., Roth, A., \& Oliveira, P. (2009). Common method bias in regression models with linear, quadratic, and interaction effects, Organizational Research Methods, 13(3), 456-476.

Shortell, S. M., \& Zajac, E. J. (1990). Perceptual and archival measures of Miles and Snow's strategic types: A comprehensive assessment of reliability and validity. Academy of Management Journal, 37(4), 817832.

Siggelkow, N. (2002). Evolution towards fit. Administrative Science Quarterly, 47(1), 25-159.

Simons, R. (1987). Accounting control systems and business strategy: an empirical analysis. Accounting, Organisations and Society, 12(4), 357-374.

Simons, R. (1995). Levers of Control. Boston: Harvard University Press.

Snell, S. A. (1992). Control theory in strategic human resource management: The mediating effect of administrative information. Academy of Management Journal, 35(2), 292-327.

Speklé, R. (2001). Explaining management control structure variety: a transaction cost economics perspective. Accounting Organisations and Society, 26(4-5), 419-441.

Thiem, A., Baumgartner, M., \& Bol, D. (2015). Still lost in translation! A correction of three misunderstandings between configurational comparativists and regressional analysts. Comparative Political Studies, DOI: 10.1177/0010414014565892

Van de Ven, A. H., Delbecq, A. L., \& Koenig, R. (1976). Determinants of coordination modes within organizations. American Sociological Review, 41(2), 322-338.

Van der Stede, W. A. (2000). The relationship between two consequences of budgetary controls: Budgetary slack creation and managerial short-term orientation. Accounting, Organizations and Society, 25(6), 609-622.

Van der Stede, W. A., Chow, C. W., \& Lin, T. W. (2006). Strategy, choice of performance measures, and performance. Behavioural Research in Accounting, 18, 185-205.

Widener, S. K. (2007). An empirical analysis of the levers of control framework. Accounting Organizations and Society, 32(7-8), 757-788. 


\section{Appendix A. Extract of survey instrument}

\begin{tabular}{ll}
\hline Survey items & Anchors \\
\hline
\end{tabular}

Diagnostic control

To what extent does the top management team use budgets (performance measurement systems) for the following

1. Identify critical performance variables (i.e. factors that indicate achievement of current strategy)

2. Set targets for critical performance variables

3. Monitor progress towards critical performance targets

4. Provide information to correct deviations from preset performance targets

5. Review key areas of performance

Interactive control

To what extent does the top management team use budgets (performance measurement systems) for the following

1. Provide a recurring and frequent agenda for top management activities

2. Provide a recurring and frequent agenda for subordinate activities

3. Enable continual challenge and debate of underlying data, assumptions and action plans with subordinates and peers

4. Focus attention on strategic uncertainties (i.e. factors that may invalidate current strategy or provide opportunities for new strategic initiatives)

5. Encourage and facilitate dialogue and information sharing with subordinates

Tightness

The following questions relate to pre-established targets set for subordinates of the top management team (e.g. senior managers that report directly to a member of the top management team). These targets or goals may be financial (e.g. budget targets) or related to other performance dimensions.

1. How flexible are subordinate performance targets once they have been set? (Reverse coded)

2. How frequently are subordinates consulted about performance target achievement? (Reverse coded)

3. To what extent are written explanations for variances from target performance levels required from subordinates?

4. To what extent are subordinate evaluations predominantly based on achievement of performance targets?

Measure diversity

To what extent are measures related to the following dimensions used to evaluate subordinate performance?

1. Customer (e.g. market share, satisfaction, retention)

2. Employee (e.g. employee satisfaction, turnover, workforce capabilities and development)

3. Operational Process (e.g. productivity, safety, cycle time)

4. Innovation (e.g. R\&D, new product/service success, development cycle time)

5. Quality (e.g. product/service quality, defects, awards)

6. Social Responsibility (e.g. environmental compliance, community impact, public image)
Very low extent / Very high extent

Very low extent / Very high extent

Very inflexible / Very flexible

Very frequently (daily) / Monthly / Very infrequently (quarterly or longer)

Very low extent / Very high extent

Very low extent / Very high extent

N/A / Very low extent / Very high extent 
7. Other Dimension (please elaborate)

Incentive compensation

Please indicate the extent to which...

1. The financial rewards of subordinates increase as actual performance increasingly exceeds targets

2. Subordinates whose performance relative to targets is among the top $25 \%$ are given larger financial rewards than those given to managers among the bottom $25 \%$

3. Compensation contracts clearly specify how compensation is related to subordinate performance relative to performance targets

Incentive determination

1. What is the usual basis for determining performance-based or bonus compensation for subordinates?

Determined Subjectively (based on top management assessment) / Intermediate / Determined Objectively (based on pre-determined formulas or targets)

Structure

1. Indicate how control information is typically communicated in your SBU

2. Indicate the accessibility of operational information in your SBU

3. Indicate the content of work-related communication between top management and subordinates

4. In general, the operating management philosophy in my SBU favours

5. In general, the operating management philosophy in my SBU favours

Through highly structured, formal channels of communication / Through very open, informal channels of communication

Highly restrictive access to important operational information / Free flow of important operational information throughout the SBU

Top management decisions and mandates, instructional, direction giving / Information and idea sharing, consultative, advice giving

Emphasis on giving the most say in decision making to formal line managers / Emphasis on giving the most say to the expert in a given situation even if this means bypassing formal line authority

Emphasis on specialisation and top level coordination / Emphasis on initiative and adaptation to the local situation

Input control

1. How extensive is the recruitment and selection process (e.g. search for candidates, use of tests, multiple interviews) for a managerial position?

2. How much importance is placed on selecting managers who have attitudes and values aligned to the SBU, not just on technical competence?

3. How much importance is placed on training and development of managers in your SBU?

4. To what extent are training and development processes used to reinforce SBU objectives, expectations and norms?

Not very extensive / Very extensive

Very little / A great deal

Very low extent / Very high extent 
Management control effectiveness

Performance management systems are the combination of systems and processes referred to in this survey that are used by your SBU (e.g. planning, accounting, evaluation/reward systems, structure, management processes, HR procedures and organisational statements and values).

i) How important are the following priorities for your SBU?

ii) To what extent does your performance management system contribute to achieving each priority?

1. Improving efficiency

2. Being innovative

3. Adapting to changing business demands

4. Coordinating work between sub-units

5. Aligning subordinate actions to SBU goals

\section{Strategic type}

Please read the following descriptions of four types of firms. None of the types is inherently "good" or "bad". Using industry competitors as a frame of reference, and considering your SBU as a whole, which type best describes your SBU

A. - Firm A maintains a "niche" within its market by offering a relatively stable set of products/services.

- Generally Firm A is not at the forefront of new service/product market developments.

- It tends to ignore changes that have no direct impact on current areas of operation and concentrates instead on doing the best job possible in its existing arena.

B. - Firm B maintains a relatively stable base of products/services while at the same time moving to meet selected, promising new product/service market developments.

- $\quad$ The Firm is seldom "first in" with new products/services.

- However, by carefully monitoring the actions of institutions like Firm C (below), Firm B attempts to follow with a more cost-efficient or well-conceived product/service.

C. - Firm $\mathrm{C}$ makes relatively frequent changes (especially additions to) its set of products/services.

- It consistently attempts to pioneer by being "first in" in new areas of market activity, even if not all of these efforts ultimately prove to be highly successful.

- $\quad$ Firm $C$ responds rapidly to early signals of market needs or opportunities.

D. - Firm D cannot be clearly characterised in terms of its approach to changing its products/services or markets.

- It doesn't have a consistent pattern on this dimension.

- Sometimes the Firm will be an early entrant into new fields of opportunity, sometimes it will move into new fields only after considerable evidence of potential success, sometimes it will not make product/service or market changes unless forced to by external changes. 


\section{Appendix B. Overview of QCA}

Qualitative comparative analysis (QCA) refers to a range of analytical methods grounded in set theory. One distinguishing characteristics is that QCA is not a statistical method but one that is based on logical relations between sets. As Rihoux and Marx (2013 p. 168) explain:

"A set theoretic approach starts from the idea that attributes of cases are best described in set relations and not in terms of variables. Variables aim to capture a dimension of variation across cases and distribute cases on this variation. A set assesses whether, or to what degree, a case is a member of a set and then analyses the intersection between sets."

As an illustration, consider an example with two $M C$ practices ( $A$ and $B$ ) hypothesized to have an association with MC effectiveness (Y) (Bedford \& Sandelin, 2015). Assuming that each MC practice can take only one of two values, either 1 or 0 to indicate high and low use, then there are a total of four possible combinations (i.e. sets) to which a firm can be a member. Using set-theoretic notation, where " $\sim$ " refers to the logical operator not and " $\bullet$ " denotes the logical operator and, the possible sets in this example are $A \bullet B, A \bullet \sim B, \sim A \bullet B$, and $\sim A \bullet \sim B$ (e.g. the second set refers to the combination of $A$ and not $B$, which corresponds to a high use of practice $A$ and a low use of practice $B)$. Firms in each set may have either the outcome of high MC effectiveness present ( $Y$ ) or absent $(\sim Y)$. The analysis proceeds by examining the overlap between firm membership in the sets of $\mathrm{MC}$ practices and the outcome. These relations are displayed graphically in Figure 1 . In this example the set of firms that combine a high use of $A$ with a high use of $B$ have the greatest overlap with the set of firms with high $M C$ effectiveness $(Y)$. This suggests that firms with the combination $A \bullet B$ consistently achieve the outcome while firms with other combinations do not.

\section{$<$ Insert Figure 1 about here $>$}

To assess the degree of significance of a particular combination QCA calculates a consistency score, which is analogous to a $p$-value in regression analyses. When using binary values, consistency is calculated as the proportion of cases in a set that display the outcome. For example, if there are 10 firms empirically observed with the combination $A \bullet B$ and 9 of these firms display the outcome of high $M C$ effectiveness and 1 does not, then consistency would equal 0.9. Another score, called coverage, is similar to a r-square value, as it indicates the degree to which a particular combination explains the outcome. Coverage represents the percentage of firms with the outcome represented by a particular combination of MC practices. If there are 18 firms that display the outcome in the sample relating to Figure 1 , then the coverage of $A \bullet B$, which contains 9 firms with high $M C$ effectiveness, would be $0.5 .^{22}$

The example in Figure 1 is based on binary values (referred to as crisp set QCA). However, organizational attributes are seldom dichotomous in nature. Fuzzy set QCA allows sets to be defined by continuous values and treats set membership as one of degree. Empirical application of fsQCA proceeds in three main steps (Fiss, 2011). The first step, called calibration, determines the degree of membership each firm has in the sets of interest. This process involves calculating fuzzy set membership scores on the outcome and each attribute from raw measurements for each firm. To calculate membership scores, threshold values corresponding to full membership, full nonmembership, and the crossover point, need to be specified. Using these thresholds raw scores are rescaled to fuzzy set membership values between 0 (full non-membership) and 1 (full membership). For example, assume that the MC practices in Figure 1 are measured on seven-point scales with the value of 1 corresponding to a low use and 7 indicating a high use of the practice. This naturally leads to a raw score of 7 to indicate "fully in" the set of firms that have a high use of the practice and a

\footnotetext{
${ }^{22}$ Refer to Ragin (2008, pp. 44-68) and Schneider and Wagemann (2012, p. 126) for the method of calculating consistency and coverage for fuzzy sets.
} 
raw score of 1 corresponding to "fully out" of this set, which would mean that they are fully in the set with a low use of this practice. A score of 4 is set as the crossover point as this is the intermediate position between high and low use of the practice.

The second step is to convert the fuzzy set data into what is called a truth table. The rows of the truth table represent each unique combination of MC practices. A truth table has a total of $2^{k}$ rows where $k$ is the number of attributes in the analysis. For instance, with two attributes the truth table for Figure 1 has four rows. Firms are allocated to rows based on their fuzzy set membership values. Mathematically a firm can only have membership in a single truth table row (Ragin, 2008; Schneider \& Wagemann, 2012). For example, if a firm has a fuzzy set score of 0.7 for practice $A$, and a score of 0.2 for practice $B$, then it would be allocated to the row corresponding to $A \bullet \sim B$. All firms with $A>0.5$ and $B<0.5$ would be assigned to this row, while firms with other combinations of $A$ and $B$ to different rows (e.g. firms with $A>0.5$ and $B>0.5$ are allocated to $A \bullet B$ ).

The objective of constructing a truth table is to identify which, if any, combinations of attributes consistently result in an outcome. This requires two criteria to be specified. The first is to determine the number of observations (e.g. firms) required in a row for it to be considered valid empirical evidence. For large sample studies the literature recommends setting a frequency threshold greater than one while retaining at least 70 to 80 percent of observations in the sample (Greckhamer et al. 2013; Ragin, 2008). This study uses a frequency threshold of two which retains 72 percent of the sample. The second is to specify the minimum consistency threshold. Recent literature recommends a minimum threshold of 0.80 (Fiss, 2011; Greckhamer et al., 2013). Schneider and Wagemann (2012, pp. 127-8) caution that researchers should not justify consistency thresholds solely through reference to those used in prior research. One guideline they suggest, and which is applied in the literature, is to select a threshold that corresponds to a break in the distribution of consistency scores. Rows with consistency scores above the threshold are coded as 1 , meaning that firms in those rows consistently display the outcome, whilst the remaining rows are coded 0 on the outcome.

In the third step an algorithm based on Boolean algebra assesses the commonalities between truth table rows that display the outcome. For example, if empirical evidence shows that firms have high $M C$ effectiveness with either $A \bullet B \bullet C$ (read: $A$ and $B$ and $C$ ) or $A \bullet B \bullet \sim C$ (read: $A$ and $B$ and not $C$ ) then the solution can be logically reduced to $A \bullet B$. This example implies that $C$ is a redundant $M C$ practice, as whether this practice is present or absent does not affect achievement of the outcome. An important issue with this process is that some truth table rows will not be populated by firms, either because certain combinations are infeasible in practice or there is insufficient empirical evidence. This problem of "limited diversity" is overcome in fsQCA by using counterfactual analysis (Ragin, 2008). Counterfactual analysis incorporates theoretical and substantive knowledge with empirical evidence to reduce solution complexity. This procedure results in a distinction between core and peripheral practices. Core MC practices are those with the strongest empirical support for an association with the outcome whereas peripheral MC practices display weaker support (Fiss, 2011; Ragin, 2008). More specifically, counterfactual analysis produces two solutions termed the parsimonious solution and the intermediate solution. The difference between these solutions depends on the nature of the counterfactuals. Consider for example that empirical evidence shows $A \bullet B \bullet \sim C$ to consistently result in the outcome but there is no evidence for the combination $\mathrm{A} \bullet \mathrm{B} \bullet \mathrm{C}$. If theory associates $\mathrm{C}$ with the outcome then it is known as an easy counterfactual. If there is no theoretical basis to make this claim then it is a difficult counterfactual. The parsimonious solution includes both easy and difficult counterfactuals, while the intermediate solution includes only easy counterfactuals. Core practices appear in both solutions, while peripheral practices only appear in the intermediate solution (Ragin, 2008). In this study the theoretical expectations those reported in Table 1. 
There are a number of additional issues to consider with QCA. First, the standard application of QCA relates to tests of sufficiency not necessity (Mackie, 1965). For instance, in Figure 1, the combination $A \bullet B$ is determined to be sufficient for high $M C$ effectiveness, but it is not necessary as there is still a significant area of the outcome that is not covered, indicating that it is not the only way of achieving the outcome. Claims of necessity can also extend to individual attributes. For example, in the results of this study for each strategic context (Table 4) there are a number of attributes that appear across all solutions (e.g. interactive control for prospectors). However, to make this claim requires a separate test for necessity. As necessity is a stronger claim than sufficiency it is subject to a more stringent consistency threshold (Ragin, 2008; Schneider \& Wagemann, 2012). In this study each attribute is assessed separately for necessity using a consistency threshold of 0.90 . No MC practice is found to be individually necessary in either strategic context.

Second, there is the issue of logical contradictions (Schneider \& Wagemann, 2012). One type of logical contradiction occurs when a truth table row meets the consistency threshold of the analysis, but one or more of the empirical cases that are members of this row $(X>0.5)$ are not members of the outcome $(Y<0.5)$. Assessing the presence of logical contradictions requires visual inspection of the members of each truth table row meeting the consistency threshold. In this study some truth table rows contain logical contradictions, but in all instances these represent a minority of cases. All truth table rows meeting the consistency and frequency thresholds are retained (Schneider \& Wagemann, 2012). Another logical contradiction is caused when a truth table row is found to be both sufficient for the presence and the absence of the outcome (Cooper \& Glaesser, 2011). To assess this possibility, the consistency scores of truth table rows in the analysis (Table 4) are compared to the consistency scores of the same rows for an analysis on the absence of the outcome, that is, low MC effectiveness (Schneider \& Wagemann, 2012). Comparisons indicate that the consistency scores are significantly different and well below the threshold of 0.80 when the outcome is negated.

Finally, there is a concern that QCA results lack generalizability because of potential sample selection biases. The main contention is that QCA selects on the dependent variable, thereby restricting observations to instances where a phenomenon is present and ignoring cases in which the phenomenon is absent. With conventional statistical approaches this is a serious concern as inferences from the analysis would not account for instances where the predicted causal (independent) variables fail to achieve the outcome. While this concern in relation to QCA is discussed elsewhere (Ragin, 1997, 2008), two points are worth noting here. First, whether or not this is a consideration depends on whether one is testing for sufficiency or necessity. The main tests in this study are ones of sufficiency, which groups firms based on the independent variables, not the dependent variable. That is, firms with the same MC practices (the independent variables) are grouped together regardless of their score for $M C$ effectiveness (the dependent variable). The analysis proceeds by examining whether firms with a particular set of MC practices consistently lead to the outcome or not (i.e. high MC effectiveness). Tests for sufficiency, therefore, take into account instances of both the presence and absence of the outcome. Second, while tests of necessity do select on the dependent variable, it is important to note that QCA is not based on the same set of assumptions as conventional statistical methods, and additionally, tend to assess substantively different research questions. Tests of necessity attempt to establish a relationship that holds only for instances where the outcome is present. For instance, to validate the statement that "prospector firms with high MC effectiveness have an organic structure" does not require consideration of prospector firms with low MC effectiveness. This is substantively different to tests for the statement that "prospectors firms with more organic structures have higher MC effectiveness", which to be 
valid requires variation on both the independent and dependent variables that is representative of the population. 
Fig. 1. Illustration of sets and set relationships (Bedford \& Sandelin, 2015)

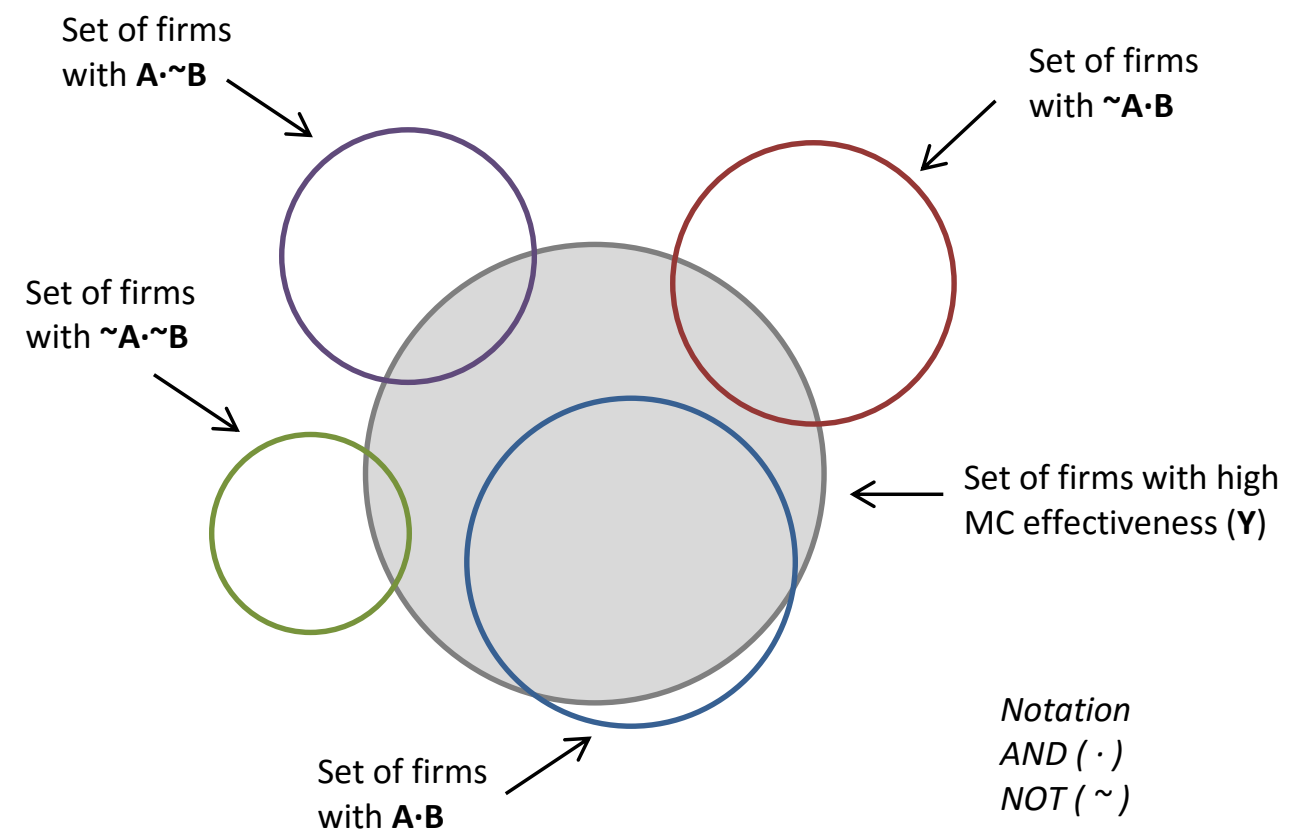


Table 1

MC practice definitions and summary of empirical evidence.

\begin{tabular}{|c|c|c|c|}
\hline MC practices & Definition & Associations $^{a}$ & $\begin{array}{l}\text { Empirical } \\
\text { evidence }^{b}\end{array}$ \\
\hline \multicolumn{4}{|l|}{ Accounting } \\
\hline $\begin{array}{l}\text { Diagnostic control use } \\
\text { (DIAG) }\end{array}$ & $\begin{array}{l}\text { Monitoring activity through deviations } \\
\text { from predetermined standards of } \\
\text { performance }\end{array}$ & $\begin{array}{l}\text { Defender }(+) \\
\text { Prospector }(-)\end{array}$ & $\mathrm{AB}, \mathrm{B}, \mathrm{BO}, \mathrm{H}, \mathrm{MF}$ \\
\hline $\begin{array}{l}\text { Interactive control use } \\
\text { (INT) }\end{array}$ & $\begin{array}{l}\text { Regular involvement in decision } \\
\text { activities of subordinates to encourage } \\
\text { debate, learning and opportunity search }\end{array}$ & $\begin{array}{l}\text { Defender }(-) \\
\text { Prospector }(+)\end{array}$ & $\mathrm{AB}, \mathrm{B}, \mathrm{BO}, \mathrm{H}$ \\
\hline Tightness (TIGHT) & $\begin{array}{l}\text { Accountability for meeting pre- } \\
\text { established performance targets: loose } \\
\text { to tight }\end{array}$ & $\begin{array}{l}\text { Defender }(+) \\
\text { Prospector }(-/+)^{\mathrm{c}}\end{array}$ & $\mathrm{AL}, \mathrm{CM}, \mathrm{S}, \mathrm{V}$ \\
\hline $\begin{array}{l}\text { Measure diversity } \\
\text { (MEAS) }\end{array}$ & $\begin{array}{l}\text { Scope of performance measures: } \\
\text { narrow to broad }\end{array}$ & $\begin{array}{l}\text { Defender }(-) \\
\text { Prospector }(+)\end{array}$ & $\begin{array}{l}\mathrm{CL}, \mathrm{D}, \mathrm{DGS}, \mathrm{LV}, \\
\text { VCL }\end{array}$ \\
\hline \multicolumn{4}{|l|}{ Compensation } \\
\hline Incentive pay (INCPAY) & $\begin{array}{l}\text { Performance-contingent financial } \\
\text { rewards }\end{array}$ & $\begin{array}{l}\text { Defender }(-) \\
\text { Prospector }(+)\end{array}$ & BG, BS, DGS, \\
\hline $\begin{array}{l}\text { Incentive determination } \\
\text { (INCDET) }\end{array}$ & $\begin{array}{l}\text { Method of determining compensation: } \\
\text { subjective to objective }\end{array}$ & $\begin{array}{l}\text { Defender }(+) \\
\text { Prospector }(-)\end{array}$ & 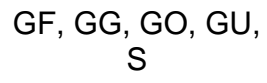 \\
\hline \multicolumn{4}{|l|}{ Administrative } \\
\hline Structure (STRUCT) & $\begin{array}{l}\text { Patterns of authority, decision-making, } \\
\text { and communication: mechanistic to } \\
\text { organic }\end{array}$ & $\begin{array}{l}\text { Defender }(-) \\
\text { Prospector }(+)\end{array}$ & $\mathrm{AL}, \mathrm{CM}, \mathrm{M}$ \\
\hline \multicolumn{4}{|l|}{ Cultural } \\
\hline Input controls (INPUT) & $\begin{array}{l}\text { Use of selection and training to align } \\
\text { individual values with the interests of the } \\
\text { firm }\end{array}$ & $\begin{array}{l}\text { Defender }(-) \\
\text { Prospector }(+)\end{array}$ & ADS, CL \\
\hline
\end{tabular}

\footnotetext{
${ }^{a}$ A positive "+" association indicates a greater emphasis on the MC practice while a negative "-" association indicates a lesser emphasis on the MC practice.

b Abbreviations: AB, Abernethy \& Brownell (1999); ADS, Abernethy, Dekker, \& Schulz (2015); AL, Auzair \& Langfield-Smith (2005); B, Bedford (2015); BG, Balkin \& Gomez-Mejia (1990); BO, Bisbe \& Otley (2004); BS, Boyd \& Salamin (2001); CL, Chenhall \& Langfield-Smith (1998); CM, Chenhall \& Morris (1995); D, Davila (2000); DGS, Dekker, Groot, \& Schoute (2013); GF, Govindarajan \& Fisher (1990); GG, Govindarajan \& Gupta (1985); GO, Govindarajan (1988); GU, Gupta (1987); H, Henri (2006a); LV, Lillis \& van Veen-Dirks (2008); M, Miller (1988); MF, Miller \& Friesen, (1982); S, Simons (1987); V, Van der Stede (2000); VCL, Van der Stede, Chow \& Lin (2006).

c Empirical research shows both positive and negative associations.
} 
Table 2

Demographic data.

Panel A: Firm size

Number of employees

1-250

251-500

116

501-1000

54

1001-2500

32

$2500+$

14

Total

400

Panel B: Industry

\section{Category}

Agriculture, forestry, fishing

Mining

Construction

Manufacturing

151

Transportation, utilities

31

Wholesale

Retail

Finance, insurance, real estate

Services

Other

3

Total

400 
Table 3

Descriptive statistics and bivariate correlations.

\begin{tabular}{|c|c|c|c|c|c|c|c|c|c|c|c|}
\hline Variable & Mean & Std Dev & 1 & 2 & 3 & 4 & 5 & 6 & 7 & 8 & 9 \\
\hline 1. Diagnostic (DIAG) & 5.51 & 0.83 & & & & & & & & & \\
\hline 2. Interactive (INT) & 4.78 & 1.03 & 0.64 & & & & & & & & \\
\hline 4. Measure diversity (MEAS) & 4.26 & 1.06 & 0.40 & 0.52 & 0.12 & & & & & & \\
\hline 5. Incentive pay (INCPAY) & 4.56 & 1.42 & 0.42 & 0.35 & 0.43 & 0.20 & & & & & \\
\hline 8. Input controls (INPUT) & 5.00 & 1.01 & 0.33 & 0.46 & 0.14 & 0.49 & 0.30 & 0.19 & 0.18 & & \\
\hline 9. MC effectiveness (MCEFFECT) & 24.27 & 7.61 & 0.49 & 0.59 & 0.19 & 0.51 & 0.27 & 0.14 & 0.23 & 0.46 & \\
\hline 10. Environmental dynamism (ENVDYM) & 3.67 & 0.83 & -0.06 & -0.01 & -0.09 & 0.11 & 0.01 & -0.14 & 0.04 & 0.06 & 0.09 \\
\hline
\end{tabular}

Correlations with an absolute value of 0.11 or higher are significant at $p<0.05$ 
Table 4

Results of fsQCA for high MC effectiveness for defender and prospector firms.

\begin{tabular}{|c|c|c|c|c|c|}
\hline \multirow[b]{2}{*}{ MC Package } & \multicolumn{2}{|c|}{ Defenders } & \multicolumn{3}{|c|}{ Prospectors } \\
\hline & $1 \mathrm{a}$ & $1 b$ & $2 a$ & $2 b$ & $2 c$ \\
\hline \multicolumn{6}{|l|}{ Accounting } \\
\hline \multicolumn{6}{|l|}{ Diagnostic } \\
\hline Interactive & $\otimes$ & $\otimes$ & & & \\
\hline $\begin{array}{l}\text { Tightness } \\
\text { Loose } \otimes / \text { tight } \bullet\end{array}$ & $\bullet$ & & $\otimes$ & & $\bullet$ \\
\hline Measure diversity & & & $\bullet$ & $\bullet$ & \\
\hline \multicolumn{6}{|l|}{ Compensation } \\
\hline Incentive pay & & & & $\bullet$ & $\bullet$ \\
\hline $\begin{array}{l}\text { Incentive determination } \\
\text { Subjective } \otimes / \text { objective } \bullet\end{array}$ & $\bullet$ & $\bullet$ & & & $\otimes$ \\
\hline \multicolumn{6}{|l|}{ Administrative } \\
\hline $\begin{array}{l}\text { Structure } \\
\text { Mechanistic } \otimes / \text { organic } \bullet\end{array}$ & $\otimes$ & & & & \\
\hline \multicolumn{6}{|l|}{ Cultural } \\
\hline Input controls & & & $\bullet$ & $\bullet$ & $\bullet$ \\
\hline Consistency & 0.88 & 0.85 & 0.85 & 0.85 & 0.85 \\
\hline Raw coverage & 0.49 & 0.47 & 0.41 & 0.50 & 0.31 \\
\hline Unique coverage & 0.08 & 0.06 & 0.02 & 0.08 & 0.01 \\
\hline Overall solution consistency & \multicolumn{2}{|c|}{0.85} & \multicolumn{3}{|c|}{0.84} \\
\hline Overall solution coverage & \multicolumn{2}{|c|}{0.55} & \multicolumn{3}{|c|}{0.53} \\
\hline
\end{tabular}

Solid circles $(\bullet)$ refer to the presence of a MC practice. Circles with a cross $(\otimes)$ designate its absence. Large circles represent core MC practices. Small circles represent peripheral MC practices. Blank spaces indicate the MC practice is redundant for achieving the outcome. 
Table 5

OLS regression results for defender firms $(n=65)$.

\begin{tabular}{|c|c|c|c|c|c|c|c|c|c|c|}
\hline & \multicolumn{10}{|c|}{ Dependent variable: $M C E F F E C T$} \\
\hline & \multicolumn{2}{|c|}{ Model 1} & \multicolumn{2}{|c|}{ Model 2} & \multicolumn{2}{|c|}{ Model 3} & \multicolumn{2}{|c|}{ Model 4} & \multicolumn{2}{|c|}{ Model 5} \\
\hline & Coefficient & t-value & Coefficient & t-value & Coefficient & t-value & Coefficient & t-value & Coefficient & t-value \\
\hline \multicolumn{11}{|l|}{ MC practices } \\
\hline$D I A G$ & 0.399 & $2.56^{\star *}$ & 0.440 & $2.79^{\star \star \star}$ & 0.472 & $3.08^{* * *}$ & 0.304 & $1.91^{*}$ & 0.188 & 1.08 \\
\hline INT & 0.053 & 0.42 & 0.051 & 0.36 & 0.077 & 0.59 & 0.028 & 0.21 & 0.094 & 0.66 \\
\hline$T I G H T$ & 0.120 & 0.86 & 0.039 & 0.27 & 0.065 & 0.45 & 0.085 & 0.61 & 0.099 & 0.67 \\
\hline MEAS & 0.170 & 1.32 & 0.107 & 0.80 & 0.118 & 0.92 & 0.229 & $1.74^{*}$ & 0.301 & $2.17^{\star *}$ \\
\hline INCPAY & 0.084 & 0.63 & 0.060 & 0.41 & 0.089 & 0.64 & 0.075 & 0.55 & 0.107 & 0.77 \\
\hline INCDET & -0.202 & -1.27 & -0.141 & -0.86 & -0.138 & -0.86 & -0.209 & -1.33 & -0.219 & -1.34 \\
\hline STRUCT & -0.037 & -0.31 & -0.065 & -0.54 & -0.119 & -1.02 & -0.009 & -0.07 & 0.100 & 0.67 \\
\hline INPUT & 0.180 & 1.43 & 0.218 & 1.67 & 0.225 & $1.75^{\star}$ & 0.226 & $1.82^{*}$ & 0.120 & 1.57 \\
\hline \multicolumn{11}{|l|}{ MC practice interactions } \\
\hline DIAG*STRUCT & -0.241 & $-1.87^{*}$ & & & & & -0.418 & $-2.74^{\star * *}$ & -0.517 & $-2.58^{\star *}$ \\
\hline$D I A G^{\star} M E A S$ & & & -0.135 & -1.03 & & & -0.027 & -0.20 & 0.034 & 0.19 \\
\hline MEAS*STRUCT & & & & & 0.086 & 0.75 & 0.296 & $2.17^{\star \star}$ & 0.309 & $2.20^{\star *}$ \\
\hline$D I A G^{*} I N C D E T$ & & & & & & & & & 0.194 & 1.30 \\
\hline$M E A S^{*} I N C D E T$ & & & & & & & & & -0.176 & -1.16 \\
\hline INCDET ${ }^{*} S T R U C T$ & & & & & & & & & -0.002 & -0.01 \\
\hline \multicolumn{11}{|l|}{ Context interactions } \\
\hline$E N V D Y N$ & -0.019 & -0.17 & -0.079 & -0.70 & -0.052 & -0.45 & -0.085 & -0.75 & -0.114 & -0.96 \\
\hline$E N V D Y N^{*} D I A G$ & 0.104 & 0.91 & -0.033 & -0.28 & & & 0.035 & 0.29 & 0.106 & 0.74 \\
\hline ENVDYN*STRUCT & -0.145 & -1.24 & & & -0.192 & -1.63 & -0.147 & -1.20 & -0.120 & -0.91 \\
\hline ENVDYN*MEAS & & & 0.011 & 0.09 & 0.065 & 0.57 & 0.069 & 0.57 & 0.110 & 0.84 \\
\hline$E N V D Y N^{*} I N C D E T$ & & & & & & & & & -0.157 & -1.17 \\
\hline Adj. $R^{2}$ & \multicolumn{2}{|c|}{$33.8 \%$} & \multicolumn{2}{|c|}{$28.0 \%$} & \multicolumn{2}{|c|}{$30.5 \%$} & \multicolumn{2}{|c|}{$36.5 \%$} & \multicolumn{2}{|c|}{$36.0 \%$} \\
\hline$F$-Value & \multicolumn{2}{|c|}{3.72} & \multicolumn{2}{|c|}{3.08} & \multicolumn{2}{|c|}{3.34} & \multicolumn{2}{|c|}{3.45} & \multicolumn{2}{|c|}{2.89} \\
\hline Sig. $F$ & \multicolumn{2}{|c|}{0.00} & \multicolumn{2}{|c|}{0.00} & \multicolumn{2}{|c|}{0.00} & \multicolumn{2}{|c|}{0.00} & \multicolumn{2}{|c|}{0.00} \\
\hline
\end{tabular}

Standardized coefficients reported. DIAG diagnostic control use of accounting, INT interactive control use of accounting, TIGHT accountability tightness (loose to tight), MEAS diversity of performance measures (narrow to broad), INCPAY incentive pay, INCDET incentive determination (subjective to objective), STRUCT firm structure (mechanistic to organic), INPUT input controls, ENVDYN environmental dynamism, MCEFFECT effectiveness of management control practices.

${ }^{*} p<0.10,{ }^{* *} p<0.05,{ }^{* * *} p<0.01$ 
Table 6

OLS regression results for prospector firms $(n=112)$.

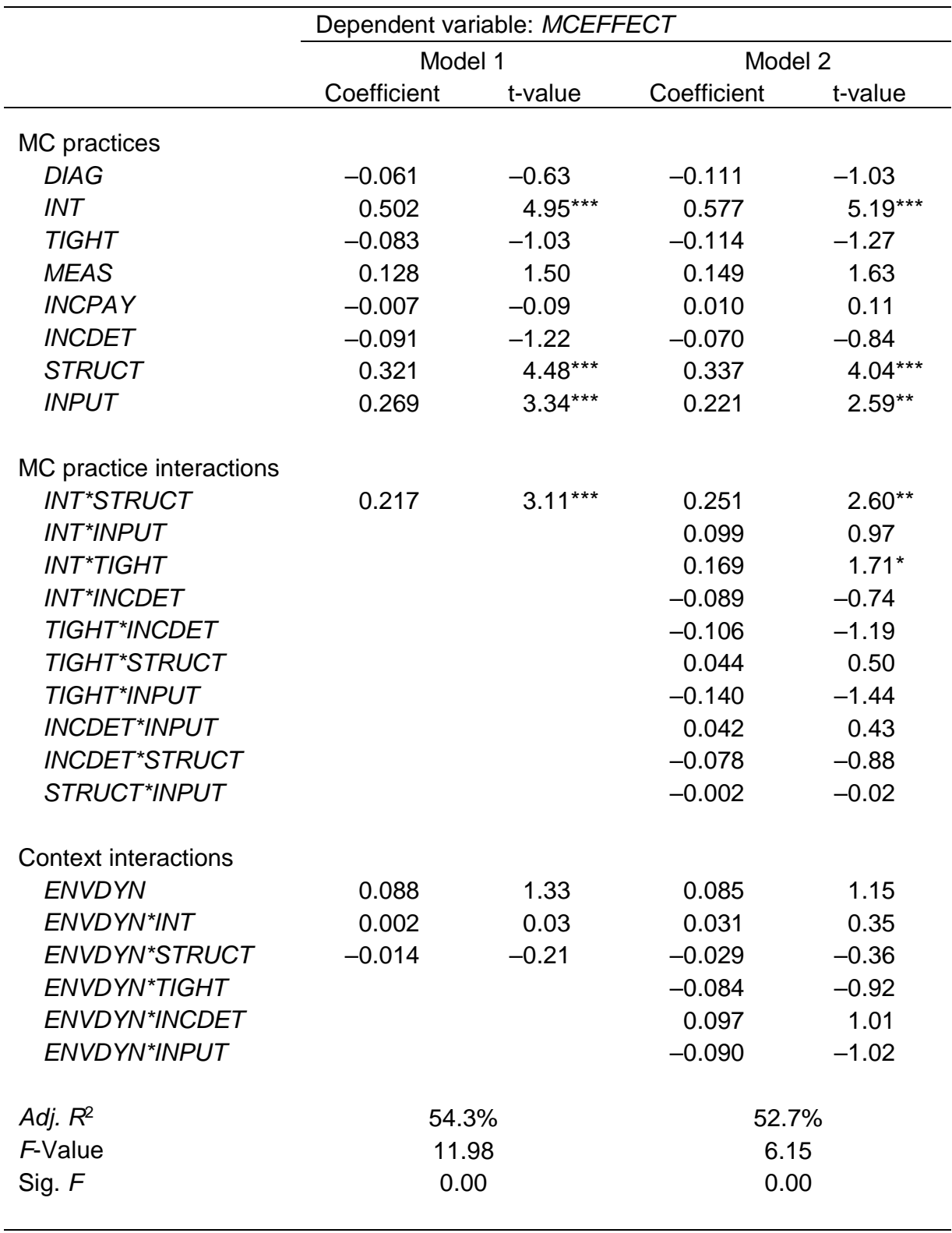

Standardized coefficients reported. DIAG diagnostic control use of accounting, INT interactive control use of accounting, TIGHT accountability tightness (loose to tight), $M E A S$ diversity of performance measures (narrow to broad), INCPAY incentive pay, INCDET incentive determination (subjective to objective), STRUCT firm structure (mechanistic to organic), INPUT input controls, ENVDYN environmental dynamism, MCEFFECT effectiveness of management control practices.

${ }^{*} p<0.10,{ }^{* *} p<0.05,{ }^{* * *} p<0.01$ 